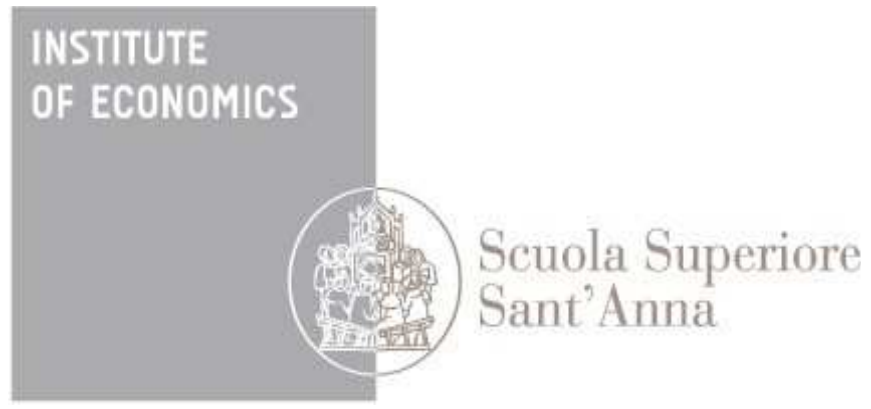

LEM | Laboratory of Economics and Management Institute of Economics

Scuola Superiore Sant'Anna

Piazza Martiri della Libertà, 33 - 56127 Pisa, Italy ph. +3905088.33 .43$

institute.economics@sssup.it

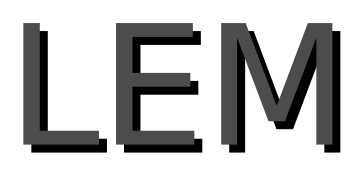

Working Paper Series

\title{
The Janus-Faced Nature of Debt: Results from a Data-Driven Cointegrated SVAR Approach
}

\author{
Mattia Guerini ${ }^{\S} *$ \\ Alessio Moneta * \\ Mauro Napoletano $§ * *$ \\ Andrea Roventini *§
}

* Institute of Economics, Scuola Superiore Sant'Anna, Pisa, Italy

Skema Business School, Sophia Antipolis, France

$\S$ Observatoire Français des Conjonctures Economiques (OFCE), Sophia Antipolis, France 


\title{
The Janus-Faced Nature of Debt: Results from a Data-Driven Cointegrated SVAR Approach
}

\author{
Mattia Guerini*, Alessio Moneta, ${ }^{\dagger}$ Mauro Napoletano $\stackrel{\ddagger}{\ddagger}$ Andrea Roventini ${ }^{\S}$
}

January 20, 2017

\begin{abstract}
In this paper, we investigate the causal effects of public and private debts on U.S. output dynamics. We estimate a battery of Cointegrated Structural Vector Autoregressive models, and we identify structural shocks by employing Independent Component Analysis, a data-driven technique which avoids ad-hoc identification choices. The econometric results suggest that the impact of debt on economic activity is fanus-faced. Public debt shocks have positive and persistent influence on economic activity. In contrast, rising private debt has a milder positive impact on GDP, but it fades out over time. The analysis of the possible transmission mechanisms reveals that public debt crowds in private consumption and investment. In contrast, mortgage debt fuels consumption and output in the short-run, but shrinks them in the mediumrun.
\end{abstract}

Keywords: Public and Private Debt, Business Cycle Fluctuations, Independent Component Analysis, SVAR Identification

JEL Classification: E32, E62, C58, H63

${ }^{*}$ Corresponding Author. Observatoire Français des Conjonctures Economiques (OFCE), France, and Scuola Superiore Sant'Anna, Pisa, Italy. mattia.guerini@sciencespo.fr

†Scuola Superiore Sant’Anna. alessio.moneta@santannapisa.it

¥Observatoire Français des Conjonctures Economiques (OFCE), France, and Université Côte d’Azur, SKEMA, CNRS, GREDEG, France, and Scuola Superiore Sant'Anna, Pisa, Italy. mauro.napoletano@sciencespo.fr

${ }^{\S}$ Scuola Superiore Sant’Anna and OFCE SciencesPo. andrea.roventini@santannapisa.it 


\section{Introduction}

This work empirically investigates the economic impact of private and public debts, by employing a battery of Cointegrated Structural Vector Autoregressive (SVAR) models, whose structural coefficients are identified employing a recently developed data-driven methodology. Our goal is to contribute to the recent debate about the role that different types of debt can have on economic dynamics.

The financial and economic crises of 2008 have intimately been intertwined with the dynamics of debt ${ }^{1}$ On the one hand, U.S. firm and household debts have been growing since the sixties until the outburst of the subprime real asset bubble in 2008 (see also Figure 1, panels B and D). On the other hand, in the aftermath the Great Recession, U.S. public debt has skyrocketed from $60 \%$ to more than $100 \%$ of GDP (see figure 1 . panel A), raising concerns about the sustainability of public finances, and more generally, about the possible detrimental effects of public debt on economic growth (Reinhart and Rogoff. 2010a).

One of the most accepted narratives of the underlying causal mechanisms linking public and private debts to real output dynamics dates back to the seminal work of Fisher (1933) and Minsky (1986), and it has recently revived by a blossoming number of contributions (from Greenwald and Stiglitz, 1993 and Bernanke et al. 1999 all the way to Koo, 2008, Eggertsson and Krugman, 2012, Gertler et al., 2010, Delli Gatti et al. 2010 Dosi et al. 2013, 2015 and the survey in Brunnermeier et al. 2012). Buoyant credit fuels debt and asset prices bubbles, which eventually get bust when a loss of confidence occurs. The consequent sharp fall in asset prices considerably worsens the balance sheets of banks, freezing interbank markets and triggering credit rationing and flight to quality phenomena. In turn, the fall in private consumption and investment paves the way to deflationary pressures, which increase the real value of debt contracts and further worsen the financial conditions of borrowers. In addition, default cascades and bank runs may lead to the collapse of some financial institutions. Eventually, governments must intervene by increasing deficit and public debt, possibly transforming a private debt crisis in sovereign one.

In line with the previous theoretical developments, a wide consensus has emerged at the empirical level about the detrimental effect of excessive credit growth on economic dynamics (see in particular Mian and Sufi, 2009, 2011, Schularick and Taylor, 2012, Jorda et al. 2013, 2016, Mian et al. 2015; Turner, 2015). These works provide robust evidence about the fact that high level of households debt and upsurges in house prices have a great explanatory power for the generation of financial crises.

On the contrary, the debate about the role of excessive public debt on macroeconomic dynamics is still open also due to scarcer available data. Empirical works have tried to detect thresholds above which public debt becomes detrimental for economic growth, and, more generally, to study the existence of a causal effects between public debt and economic growth (see Reinhart and Rogoff, 2010a|b, Reinhart et al. 2012, Herndon et al. 2013, Cecchetti et al. 2011: Checherita-Westphal and Rother, 2010, Panizza and Presbitero 2014, Egert. 2015 Eberhardt and Presbitero 2015) ${ }^{2}$ These works typically employ panel-data models and rely on annual observations from several countries. The obtained mixed results suffer from different econometric problems. Apart from the usual issue of endogeneity, another technical hurdle relates to the adoption of panel-data regressions, which implicitly assumes that the causal effect of public debt on economic growth is homogenous in all the countries in the dataset (except for country-specific fixed effects). To our knowledge, the only

\footnotetext{
${ }^{1}$ More generally, $\mathrm{Ng}$ and Wright (2013), find in the last thirty years all U.S. recessions have financial origins.

${ }^{2}$ See the survey by Panizza and Presbitero (2013) for a more detailed discussion.
} 
Public Debt to GDP

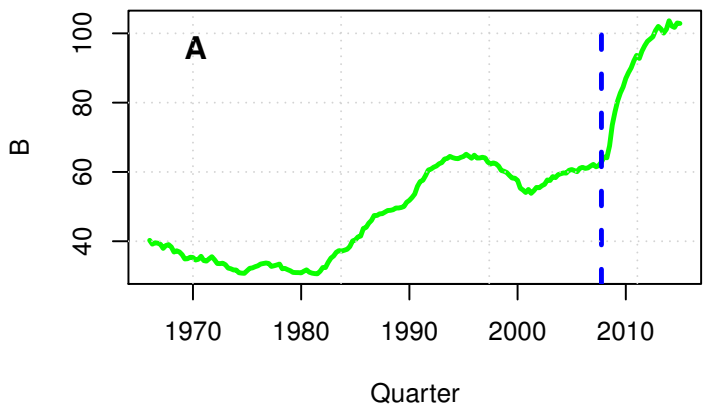

Corporate Debt to GDP

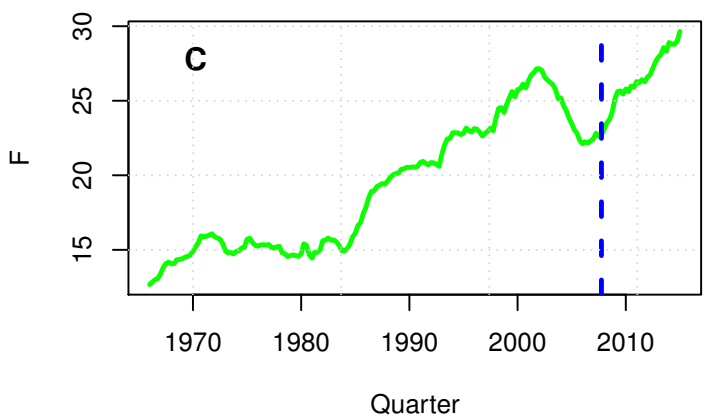

Private Debt to GDP

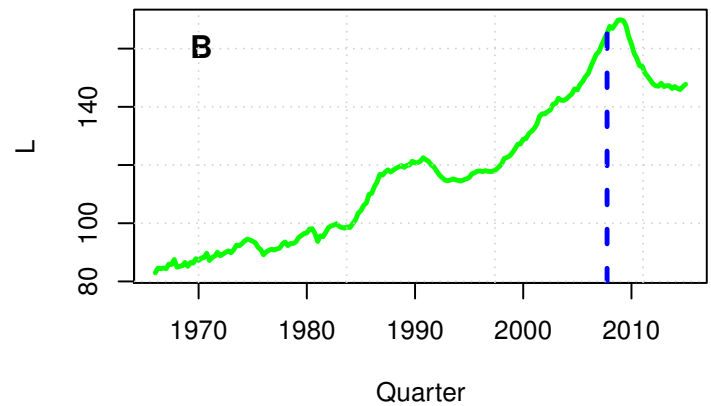

Household Debt to GDP

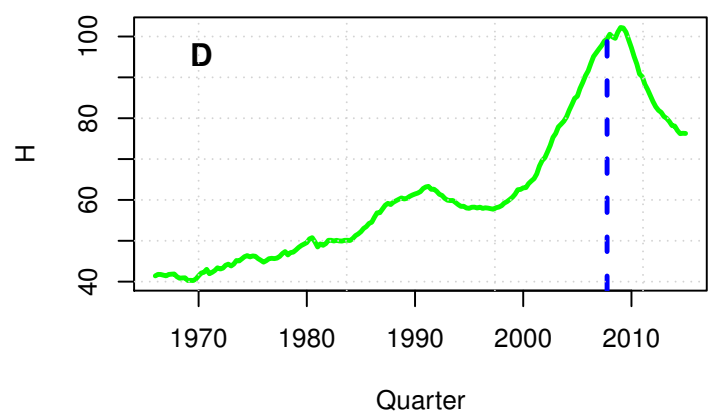

Figure 1: Various measures of debt-to-GDP. The vertical dashed line represent 2007:Q4.

exception is the work by Eberhardt and Presbitero (2015), who show the importance of country heterogeneity employing kernel estimations $3^{3}$ Finally, Jorda et al. (2014) argue that expansionary fiscal policies lose their grip if the economy enters into a financial crisis with an existing high level of public debt-to-GDP ratio.

In this work, we contribute to the aforementioned empirical research by jointly investigating the impact of public and private debt on U.S. GDP dynamics, employing a series of cointegrated SVAR models (Johansen. 1995). Our work improves upon the existing literature in several respects. First, the cointegrated SVAR approach is a way to tackle endogeneity, which has been one of the most delicate issue in the literature about public and private debt so far, and to study the dynamics effects of debt on macroeconomic variables both in the short- and in the medium-run. Second, we disentangle between different types of private debt (firm and household debt). Third, we investigate possible transmission mechanisms from private and public debt to GDP, assessing the possible crowding-out or crowding-in effects on consumption and investment. Finally, we identify structural relations by using data-driven causal search algorithms (Indipendent Component Analysis - ICA - see Moneta et al. 2013, Gourieroux et al. 2017). The ICA procedure allows us to identify structural private and public debt shocks by "letting the data speak", i.e. without resorting to any ad-hoc procedure grounded on economic theory.

We find that public debt shocks positively and persistently affect output. In that, our results thus provide

\footnotetext{
${ }^{3}$ In particular, estimating a pooled model suggests the presence of an inversely U-shaped curve, but when country heterogeneity is accounted for, the curve becomes U-shaped for most of the countries (see figure 2 in Eberhardt and Presbitero 2015).
} 
further evidence against the hypothesis that higher levels of public debt hamper GDP growth (Reinhart and Rogoff, 2010a). In fact, surges in public debt crowd-in private consumption and investment (Woodford 1990, Holmstrom and Tirole, 1998: Stiglitz, 2012), thus spurring output both in the short- and in the medium-run. On the contrary, this does not appear to be the case for private debt shocks. More specifically, we find that the positive effects of private debt shocks are milder than public debt's ones, and they fade out over time. Moreover, increasing levels of mortgage debt have a negative impact on output dynamics in the mediumrun. Such a result appears to be consistent with the hypothesis that mortgage debt inflates real asset bubbles, whose outburst triggers financial crises. (Mian and Sufi 2009). Finally, we find that the main econometric results are robust to different model specifications and to the inclusions of the Great Recession observations.

Our results suggest that debt is fanus-faced: different types of debt impact differently on economic dynamics. In particular, possible menaces to medium- and long-run output growth do not come from government debt, but rather from increasing levels of private debt. In particular, surges in household debt appear to be much more dangerous than increases in corporate debt.

The paper is organized as follows. Sections 2 and 3 describe respectively the estimation technique and the data. Sections 4 and 5 present the main results and the robustness exercises. Section 6 concludes. Two appendices integrate the paper with additional technical explanations.

\section{Methodology}

We estimate our multivariate time series model by means of a Cointegrated Vector Autoregressive (CVAR) model in its transitory formulation, using the Johansen (1995) procedure (see also Lutkepohl 1991). Being $\mathbf{Y}_{\mathbf{t}}$ the $k \times 1$ vector of variables object of investigation, the model of interest is specified as:

$$
\Delta Y_{t}=\Pi Y_{t-1}+\Theta_{1} \Delta Y_{t-1}+\cdots+\Theta_{p-1} \Delta Y_{t-p+1}+u_{t}
$$

where $\boldsymbol{\Pi}$ and $\boldsymbol{\Theta}_{\mathbf{i}}(i=1, \ldots, p-1)$ are $k \times k$ matrices and $\mathbf{u}_{\mathbf{t}}$ is a $k \times 1$ vector of error terms. Naturally, the model can also be rewritten in the more "standard" VAR specification:

$$
\mathbf{Y}_{\mathbf{t}}=\mathbf{A}_{\mathbf{1}} \mathbf{Y}_{\mathbf{t}-\mathbf{1}}+\cdots+\mathbf{A}_{\mathbf{p}} \mathbf{Y}_{\mathbf{t}-\mathbf{p}}+\mathbf{u}_{\mathbf{t}}
$$

with $\boldsymbol{\Theta}_{\mathbf{i}}=-\left(\mathbf{A}_{\mathbf{i}+\mathbf{1}}+\cdots+\mathbf{A}_{\mathbf{p}}\right)$, for $\mathbf{i}=\mathbf{1}, \ldots, \mathbf{p}-\mathbf{1}$ and $\boldsymbol{\Pi}=\boldsymbol{\alpha} \boldsymbol{\beta}^{t}=-\left(\mathbf{I}-\mathbf{A}_{\mathbf{1}}-\cdots-\mathbf{A}_{\mathbf{p}}\right)$. The matrix $\boldsymbol{\Pi}$ represents the error correction term composed by the loading matrix $\boldsymbol{\alpha}$ and by the cointegration vector $\boldsymbol{\beta}^{t}$.

Estimation of the model in equation 1 is preferred since it allows the estimation of the possible existing cointegrating relations which are contained in $\beta^{\mathbf{t}} \mathbf{Y}_{\mathbf{t}-\mathbf{1}}$, coping with the possible common trends and with the non-stationarity that our variables of interest might exhibit.

Both equations 1 and 2 are reduced-form models and share the same vector of residuals $\mathbf{u}_{\mathbf{t}}$. By rotating the reduced form models, pre-multiplying both sides of the equation by a matrix $\boldsymbol{\Gamma}_{\mathbf{0}}$, one can obtain the Structural-VAR (SVAR) model, where structural shocks $\varepsilon_{t}$ are meant to represent the "true" economic shocks affecting the system:

$$
\Gamma_{0} \mathbf{Y}_{\mathrm{t}}=\boldsymbol{\Gamma}_{1} \mathbf{Y}_{\mathrm{t}-1}+\cdots+\boldsymbol{\Gamma}_{\mathrm{p}} \mathbf{Y}_{\mathrm{t}-\mathrm{p}}+\varepsilon_{\mathrm{t}}
$$

where $\boldsymbol{\Gamma}_{\mathbf{i}}=\boldsymbol{\Gamma}_{\mathbf{0}} \mathbf{A}_{\mathbf{i}}$ for $\mathbf{i}=\mathbf{1}, \ldots, \mathbf{p}$ and $\varepsilon_{t}=\boldsymbol{\Gamma}_{\mathbf{0}} \mathbf{u}_{\mathbf{t}}$. However, even by assuming orthogonal structural shocks, 
the identification problem requires $k(k-1) / 2$ restrictions on the matrix $\boldsymbol{\Gamma}_{\mathbf{0}}$. Such restrictions are typically derived from economic theory, and therefore additional assumptions and subjective choices are required. The standard solution to this problem is the Cholesky decomposition, which requires the assumptions of both contemporaneous acyclicity and specific causal order, dictated by economic theory.

Independent Component Analysis (ICA) allows us to relax the second assumption by recovering the matrix $\Gamma_{0}$ with a data-driven procedure (see Hyvarinen et al. 2010, Moneta et al. 2013, Gourieroux et al. 2017) ${ }^{4}$ In this way, the causal order of the SVAR is not dictated by debatable theoretical considerations, but one can achieve identification by letting the data speak. More specifically, given $\mathbf{u}_{\mathbf{t}}=\boldsymbol{\Gamma}_{\mathbf{0}}^{-1} \varepsilon_{\mathbf{t}}$, the ICA approach focuses on the interpretation of the reduced form residuals $\mathbf{u}_{\mathbf{t}}$ as linear combinations of the structural shocks $\varepsilon_{t}$ which have been combined by the mixing matrix $\boldsymbol{\Gamma}_{\mathbf{0}}^{\mathbf{- 1}}$. Under the assumptions that (i) $\varepsilon_{1 t}, \ldots, \varepsilon_{k t}$ are mutually independent (i.e. the joint probability density function factorizes as $f\left(\varepsilon_{1 t}, \ldots, \varepsilon_{k t}\right)=f\left(\varepsilon_{1 t}\right) \cdot \ldots \cdot f\left(\varepsilon_{k t}\right)$ ); and (ii) each shock $\varepsilon_{1 t}, \ldots, \varepsilon_{k t}$ is not normally distributed (with the exception of at most one Gaussian shock), ICA is able to recover the matrix $\Gamma_{0}$. The gist of the ICA approach $5^{5}$ is to search among all the possible linear combinations of $\mathbf{u}_{\mathbf{t}}$, the one that minimizes their mutual statistical dependence, measured by mutual information, defined as:

$$
I\left(x_{1 t}, \ldots, x_{k t}\right)=\sum_{i=1}^{k} H\left(x_{i t}\right)-H\left(\mathbf{x}_{t}\right),
$$

where $H$ is the differential entropy $y^{6}$ and $\mathbf{x}_{t}=\left(x_{1 t}, \ldots, x_{k t}\right)^{\prime}$ is a vector of linear combinations of $\mathbf{u}_{\mathbf{t}}=$ $\left(u_{1 t}, \ldots, u_{k t}\right)^{\prime}$. It turns out that the "directions" (i.e. transformations of the data) that minimizes mutual information can be found only if the data are non-Gaussian as Gaussian variables have the largest entropy among all random variables of equal variance 7

Following Hyvarinen et al. (2010), we also assume that the VAR residuals $\mathbf{u}_{\mathbf{t}}$ can be represented as a Linear Non-Gaussian Acyclic Model (LiNGAM), so that the contemporaneous causal structure can be represented as a Directed Acyclic Graph (DAG). This assumption allows us to apply a causal search algorithm, such as the one presented in Appendix A (see Shimizu et al. 2006, Hyvarinen et al. 2010, Moneta et al. 2013), which allows us to achieve a data-driven identification, directly comparable to a Cholesky decomposition, without any a priori theoretical commitment.

After having identified and estimated the model in its structural form, in order to analyze the effects that a shock to a debt variable has on GDP, we estimate Impulse Response Functions (IRF) with their bootstrapped confidence intervals and we formally test whether the effects are significantly different from zero. Following Lutkepohl (1991), the impulse response analysis in cointegrated systems can be conducted in the same way as for stationary systems, hence no particular issue in the estimation of IRF arises. In particular, to estimate

\footnotetext{
${ }^{4}$ This identification strategy builds on the previous works by by Swanson and Granger (1997); Bessler and Lee (2002); Demiralp and Hoover 2003); Moneta (2008). Recently also Bayesian strategies have been used to tackle the same issue (see Ahelegbey et al. 2016).

${ }^{5}$ For more details about Independent Component Analysis, its assumptions, algorithms and related concepts see Hyvarinen et al. (2001) and references therein.

${ }^{0}$ The differential entropy $H$ of a random vector $\mathbf{x}$ with probability density $f(\mathbf{x})$ is defined as $H(\mathbf{x})=-\int f(\mathbf{x}) \log f(\mathbf{x}) d \mathbf{x}$.

${ }^{7}$ It also turns out that the independent components $\varepsilon_{1 t}, \ldots, \varepsilon_{k t}$ can be estimated by minimizing mutual information or, equivalently, by finding linear combinations of the data in which negentropy, a measure of non-Gaussianity, is maximized. Negentropy $J$ of a random vector $\mathbf{x}$ with differential entropy $H(\mathbf{x})$ is defined as $J(\mathbf{x})=H\left(\mathbf{x}_{\text {gauss }}\right)-H(\mathbf{x})$, where $\mathbf{x}_{\text {gauss }}$ is a Gaussian random variable of the same covariance matrix as $\mathbf{x}$.
} 


\begin{tabular}{ll}
\hline Label & Variable Description \\
\hline Y & Real Gross Domestic Product \\
B & Real Federal Debt: Total Public Debt \\
L & Real Total Credit to Private Non-Financial Sector \\
$\mathrm{F}$ & Real Non-Financial Corporate Business Debt Securities \\
$\mathrm{H}$ & Real Mortgage Debt Outstanding \\
$\mathrm{I}$ & Real Gross Fixed Capital Formation \\
$\mathrm{C}$ & Real Personal Consumption Expenditures \\
$\mathrm{G}$ & Real Government Expenditures \\
$R_{3 m}$ & 3-Month Treasury Bill: Secondary Market Rate \\
$R_{10 y}$ & 10-Year Treasury Bill: Secondary Market Rate \\
$\mathrm{P}$ & Gross Domestic Product: Implicit Price Deflator, Index 2009=100 \\
\hline \hline
\end{tabular}

Table 1: Data description. The only two additional variables not inserted in the table which have been adopted for the robustness checks are the consumption-specific and the investment-specific deflators.

the IRF of the model one computes the vector moving average form of the model

$$
\mathbf{Y}_{\mathbf{t}}=\sum_{\mathbf{s}=\mathbf{0}}^{\infty} \boldsymbol{\Phi}_{\mathbf{s}} \mathbf{u}_{\mathbf{t}-\mathbf{s}}
$$

in which $\boldsymbol{\Phi}_{\mathbf{0}}=\mathbf{I}$ and (for $s=1,2 \ldots$ ), $\boldsymbol{\Phi}_{\mathbf{s}}=\sum_{\mathbf{j}=\mathbf{1}}^{\mathbf{s}} \mathbf{A}_{\mathbf{j}} \boldsymbol{\Phi}_{\mathbf{s}-\mathbf{j}}$ (where $\mathbf{A}_{\mathbf{j}}=\mathbf{0}$ for $j>p$ ). The impulse responses of the elements of $\mathbf{Y}_{\mathbf{t}}$ to the structural shocks $\boldsymbol{\varepsilon}_{\mathbf{t}-\mathbf{s}}(s=0,1,2, \ldots)$ corresponds to the matrices $\Psi_{s}(s=0,1,2, \ldots)$ defined as: $\Psi_{\mathbf{0}}=\boldsymbol{\Gamma}_{\mathbf{0}}^{-\mathbf{1}}$ and (for $\left.s=1,2, \ldots\right) \mathbf{\Psi}_{\mathbf{s}}=\sum_{\mathbf{j}=\mathbf{1}}^{\mathbf{s}} \mathbf{A}_{\mathbf{j}} \boldsymbol{\Psi}_{\mathbf{s}-\mathbf{j}}$. In the empirical results below, each impulse response function to the shock $\varepsilon_{t j}$ is multiplied by the standard deviation of $\varepsilon_{t j}$, so that the responses display the effect of a one-standard-deviation shock.

\section{Data}

We employ US quarterly data drawn from the FRED database, released by the Federal Reserve of St Louis (https://research.stlouisfed.org/fred2/). We focus on the US, because our estimation and identification strategies require sufficiently long time series, which, in the case of quarterly private and mortgage debt, are publicly available only for this country. Our main sample ranges from the first quarter of 1966 to the last quarter of 2015. The variables and their summary statistics are presented in table 1 and in figure 2 Beyond GDP and different public and private debt series, we have also included in our dataset consumption, investment, government expenditure, 3-months and 10-years T-Bill rates to shed light on the possible presence and direction of relevant transmission mechanisms. All the variables have been downloaded in nominal terms and have been then deflated by means of the GDP implicit price deflator (see last line of table 1 ). However, to control for possible biases introduced by the use of a common deflator for all the variables, we have also performed some robustness check exercises adopting investment and consumption specific deflators (see table 3 for more details).

The cross correlations between the log-differences of the variables (see figure 2) provide the first glimpse of the underlying relations. First, with the exception of consumption, the correlations between public debt and all the other variables are negative. Private debt instead, measured by the total amount of credit to the private non-financial sector, is positively correlated with all the other variables in the study. This also holds 


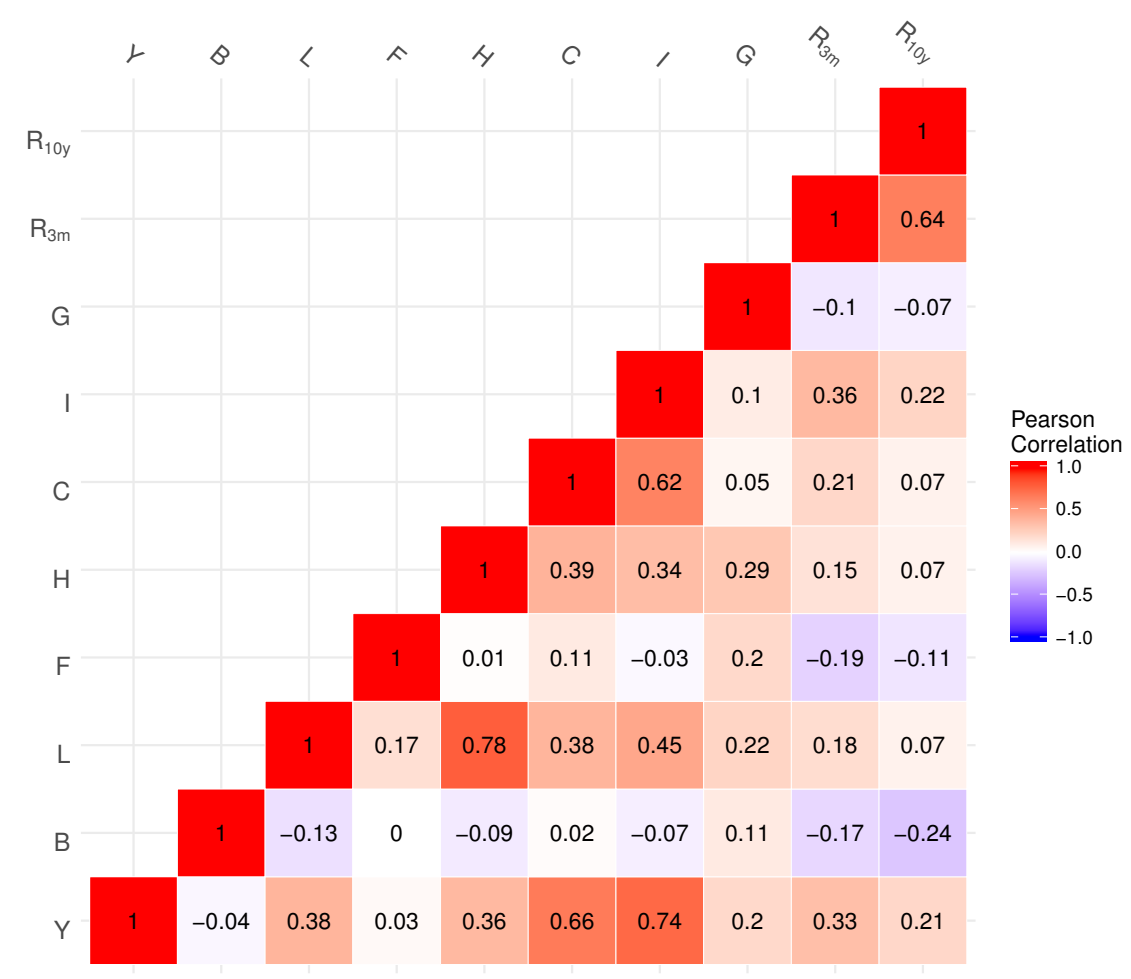

Figure 2: Cross correlations of the investigated stationarized variables.

when we disaggregate the series into corporate and household debts (the only exceptions are the correlations between corporate debt and investment and interest rates.).

Before estimating a battery of CVAR models, we study the integration order of the time series employing the Phillips and Perron (1988) test. We cannot reject the null hypothesis ( $H_{0}=$ "Presence of unit root") for all the variables in level (see table 2). On the contrary, the test rejects the null for all the variables in first difference. This suggests that all the variables of interest have one unit root.

All the models in this work share the the reduced-form specification of equation 1 , estimated using the Johansen and Juselius (1990) maximum likelihood procedure, which Silvapulle and Podivinsky (2000) demonstrate to be reasonably robust under departures from normality. The vector-error correction model specifica-

\begin{tabular}{lcccc}
\hline & \multicolumn{2}{c}{ Level } & \multicolumn{2}{c}{ Difference } \\
\hline Variable & PP-test & $p$-Value & PP-test & $p$-Value \\
\hline Y & -1.1056 & 0.9193 & -10.2842 & 0.01 \\
$\mathrm{~B}$ & -2.3184 & 0.4428 & -9.3683 & 0.01 \\
$\mathrm{~L}$ & -0.5299 & 0.9796 & -8.4035 & 0.01 \\
$\mathrm{~F}$ & -1.3161 & 0.8625 & -8.8052 & 0.01 \\
$\mathrm{H}$ & -0.1825 & 0.9900 & -4.0346 & 0.01 \\
$\mathrm{I}$ & -1.7969 & 0.6611 & -8.0843 & 0.01 \\
$\mathrm{C}$ & -0.8974 & 0.9514 & -10.4661 & 0.01 \\
$\mathrm{G}$ & -0.6104 & 0.9760 & -11.9081 & 0.01 \\
$R_{3 m}$ & -2.7281 & 0.2713 & -11.0075 & 0.01 \\
$R_{10 y}$ & -2.2819 & 0.4581 & -10.9693 & 0.01 \\
\hline \hline
\end{tabular}

Table 2: Phillips-Perron test for stationarity. 


\begin{tabular}{|c|c|c|c|c|}
\hline Model & Variables & Lag number $(p)$ & Cointegrarion relations $(r)$ & Time period \\
\hline 1 & $\mathrm{Y}, \mathrm{B}, \mathrm{L}, R_{3 m}$ & AIC: 10, HQ: 6, BIC: 5 & 1 & $1966-2015$ \\
\hline 2 & $\mathrm{Y}, \mathrm{B}, \mathrm{L}, \mathrm{I}, R_{3 m}$ & AIC: $10, \widehat{H Q}: \mathbf{6}, \mathrm{BIC}: 1$ & 2 & $1966-2015$ \\
\hline 3 & $\mathrm{Y}, \mathrm{B}, \mathrm{L}, \mathrm{C}, R_{3 m}$ & AIC: 6, HQ: 5, BIC: 1 & 2 & $1966-2015$ \\
\hline 4 & $\mathrm{Y}, \mathrm{B}, \mathrm{F}, \mathrm{I}, R_{3 m}$ & AIC: 8, HQ: 5, BIC: 2 & 2 & $1966-2015$ \\
\hline 5 & $\mathrm{Y}, \mathrm{B}, \mathrm{H}, \mathrm{C}, R_{3 m}$ & AIC: 6, HQ: 4, BIC: 2 & 1 & $1966-2015$ \\
\hline $1_{n c}$ & $\mathrm{Y}, \mathrm{B}, \mathrm{L}, R_{3 m}$ & AIC: 10, HQ: 5 , BIC: 3 & 1 & $1966-2007$ \\
\hline $2_{d f}$ & $\mathrm{Y}, \mathrm{B}, \mathrm{L}, \mathrm{I}, R_{3 m}$ & AIC: 10, HQ: 6, BIC: 1 & 1 & $1966-2015$ \\
\hline $3_{d f}$ & $\mathrm{Y}, \mathrm{B}, \mathrm{L}, \mathrm{C}, R_{3 m}$ & AIC: 6, HQ: 5, BIC: 1 & 1 & $1966-2015$ \\
\hline 6 & $\mathrm{Y}, \mathrm{B}, \mathrm{L}, R_{10 y}$ & AIC: 9, HQ: 5, BIC: 3 & 1 & $1966-2015$ \\
\hline 7 & Y, B, L, G, $R_{10 y}$ & AIC: 9, HQ: 5, BIC: 1 & 2 & $1966-2015$ \\
\hline $1_{r}$ & $\mathrm{Y}, \mathrm{B} / \mathrm{Y}, \mathrm{L} / \mathrm{Y}, R_{3 m}$ & AIC: 10, HQ: 6, BIC: 5 & 1 & $1966-2015$ \\
\hline 8 & $\mathrm{Y}, \mathrm{B}, \mathrm{F}, \mathrm{H}, \mathrm{C}, \mathrm{I}, R_{3 m}$ & AIC: 7, HQ: 2, BIC: 1 & 3 & $1966-2015$ \\
\hline $8_{r}$ & $\mathrm{Y}, \mathrm{B} / \mathrm{Y}, \mathrm{F} / \mathrm{Y}, \mathrm{H} / \mathrm{Y}, \mathrm{C}, \mathrm{I}, R_{3 m}$ & AIC: 7, HQ: 2, BIC: 1 & 3 & $1966-2015$ \\
\hline
\end{tabular}

Table 3: CVAR model specifications. settings. Subscripts $n c, d f$ and $r$ stand respectively for "no-crisis" for "alternative deflator" and for "debt measured as a ratio to GDP". The acronyms AIC, HQ, BIC represent the standard information criteria: the adopted one has been written in bold character.

tion allows us to exploit the information stemming from possible cointegrating relationships.

\section{Econometric Results}

In this section, we employ a battery of CVAR models, identified according to the data-driven ICA procedure, to investigate the effects of public and private debt on the dynamics of output, consumption and investment. The baseline specification includes GDP, total public debt, total credit to private (non-financial) sector, and the three-month T-Bill interest rate. We then augment the benchmark model, considering private consumption, firm investment, disaggregating private debt in corporate business and mortgage debt series. All the estimated model specifications are reported in table 3 , together with the reference period (1966-2015 in the benchmark specification), the lag number $p$ suggested by standard information criteria ${ }^{8}$ and the tested number $r$ of cointegration relations.

Before discussing the results derived from the identification of the structural model, we show in table 4 the estimated cointegration relations. Indeed, as discussed in Johansen and Juselius (1994), the long-run parameters $\beta$ is the same both in the reduced and structural forms, implying that the identification of the cointegration relations can be performed already in the reduced form $9^{9}$ Table 4 shows positive bivariate longrun relationships between GDP and each of the debt series.

In what follows, we first describe the results derived from the benchmark structural model (cf. section 4.1 ). We then present in section 4.2 the results of the model augmented with the consumption or investment series. In section 4.3 , we report the findings obtained employing disaggregated private debt series, also studying the crowding-out vis-à-vis crowding-in effects of public debt shocks on private consumption and investment.

\footnotetext{
${ }^{8}$ The bold in the lag selection corresponds to our choice. Where possible, we have adopted the Bayes-Schwartz Criterion (BIC). In the cases in which the adoption of such a criterion was a poor one (because residuals displayed some correlation structure) we have selected the more parsimonious between the Akaike Information Criterion (AIC) and the Hannan-Quinn Criterion (HQ). All the cointegration relations are estimated with a constant trend.

${ }^{9}$ Note that discrepancies between cointegration relations and impulse-response functions are in principle possible, since cointegration suggests a co-movement or mutual attraction among a set of variables, while an impulse response function provides the effect (over time) of an exogenous intervention on a single variable on another variable.
} 


\begin{tabular}{|c|c|c|c|c|c|c|c|c|}
\hline Variable & ID 1 & $I D_{2}$ & $r=2)$ & & $(r=2)$ & $I D 4$ & $r=2)$ & ID 5 \\
\hline $\mathrm{Y}$ & 1 & 1 & 0 & 1 & 0 & 1 & 0 & 1 \\
\hline B & -0.0052 & 0 & 1 & 0 & 1 & 0 & 1 & -0.1763 \\
\hline $\mathrm{L}$ & -0.7092 & -3.3690 & -21.2617 & -0.5813 & -22.9709 & & & \\
\hline $\mathrm{F}$ & & & & & & -0.3506 & -2.1589 & \\
\hline $\mathrm{H}$ & & & & & & & & -0.3714 \\
\hline I & & 3.6784 & 27.6748 & & & -0.4433 & 1.7958 & \\
\hline $\mathrm{C}$ & & & & -0.1832 & 29.1448 & & & -0.1634 \\
\hline $\mathrm{R}$ & -1.2553 & -10.7382 & -71.2981 & -1.1836 & -25.0376 & 0.3161 & 2.6357 & -1.8142 \\
\hline const. & -5.7968 & 1.0895 & 54.1615 & -4.8187 & -151.8507 & -7.4530 & -0.1093 & -5.5472 \\
\hline
\end{tabular}

Table 4: Estimated cointegration relations $\left(\beta^{t}\right)$.

\subsection{Baseline model}

The baseline regression we consider here is a four-dimensional CVAR containing output, government debt, private debt, ant the 3-months T-Bill interest rate (cf. table 3). The latter variable controls also for possible monetary-policy effects.

Figure 3 shows the causal matrices of the structural CVAR model, identified with the ICA data-driven causal search procedure. The first matrix on the left (lag 0 ) represents $B=I-\Gamma_{0}$. The "agnostic" selection identification strategy for the Cholesky decomposition suggests a contemporaneous causal structure in which only private debt has a positive effect on GDP. The other two variables does not seem to have any contemporaneous impact.
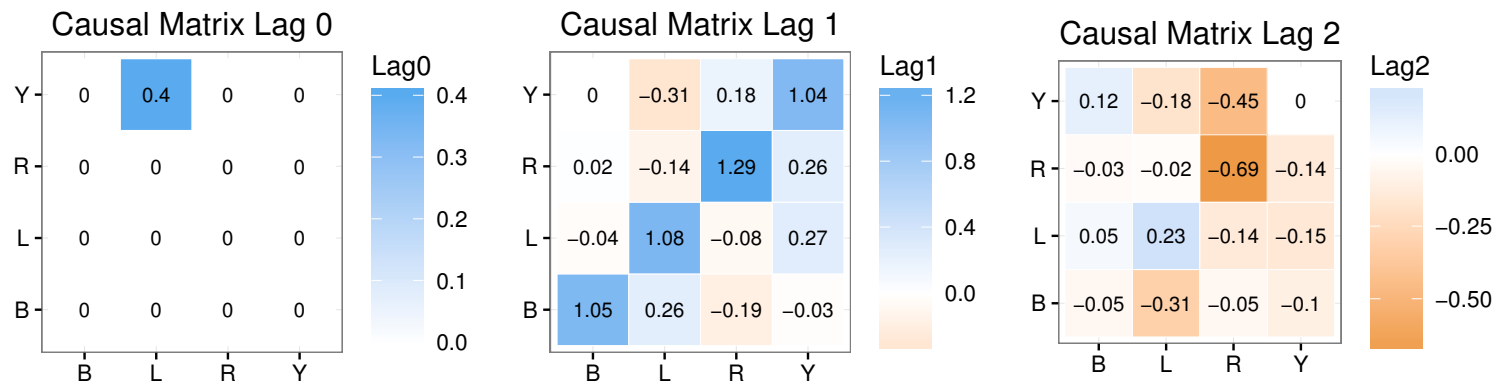

Figure 3: SVAR causal matrices up to the $2^{\text {nd }}$ lag for the baseline model 1 . The variables below the matrices cause the ones on the left.

Let us now consider the impact of public and private debts on GDP dynamics. The estimated impulse response functions (IRFs) are depicted in figure $4^{10}$ We find that a positive shock to public debt persistently and positively spurs output growth. Such a result contributes to the debate on the positive or negative effect of public debt on GDP growth with a fresh piece of evidence obtained with a data-driven identification methodology in a cointegrated VAR framework. In that, it should be immune of possible theoretical choices and biases. In line with the evidence discussed in the introduction (see Jorda et al. 2013), private debt shocks

\footnotetext{
${ }^{10}$ The IRFs are robust to different model estimation strategy, such as the level-VAR estimated with OLS. The represented confidence intervals are calculated via bootstrapping for the $5 \%$ and at the $95 \%$ levels. Note that the fact that the IRFs do not necessarily converge to zero level is due to the fact that we estimate the model in level, which is consistent with the Johansen (1995) procedure.
} 

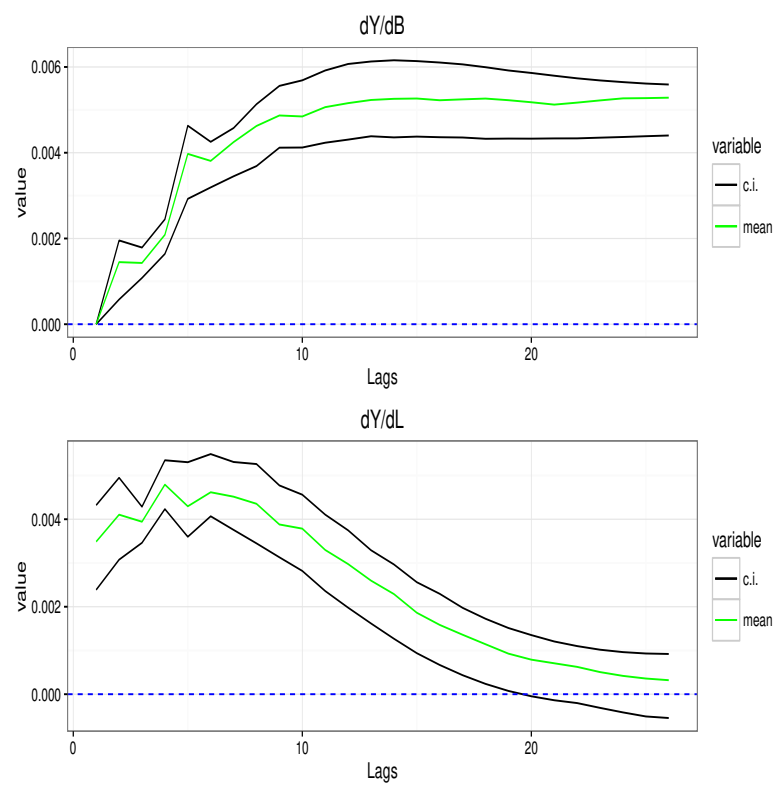

Figure 4: Impulse response functions, model 1. Response of GDP to a $1 \%$ standard deviation shock to public debt (upper panel) and to private debt (lower panel). 95\% confidence bands obtained via bootstrap.

increase GDP in the short-run, but have negligible effects on output at longer horizons (cf. figure 4).

\subsection{Augmented models}

Let us now augment the baseline model (cf. table 3) by adding either aggregate investment (model 2) or private consumption (model 3). The richer specifications could shed further light on the possible transmission mechanisms of private and public debt.

Figure 5 represents the matrices of the structural VARs for the models 2 (top row) and 3 (bottom row). The change of variables between the two models leads to quite different contemporaneous causal structures, which our identification strategy is flexible enough to capture. In model 2, GDP pushes private debt and private investment, suggesting the possible presence of an accelerator mechanism (see figure 5). The positive effect of private debt on investment highlights the link between the financial structure of firms and households and their real decisions about investment. In model 3, instead, the unique significant contemporaneous causal effect is played by consumption on output, which is in line with the co-movements found by Stock and Watson (1999) in the U.S. at the business cycle frequencies. While the differences in the observed causal structures of the three models could be possibly be due to the different variables included in the cointegrated SVARs, the causal matrices at lags one and two are pretty similar and consistent also with the ones of the baseline specification (cf. figure 5 .

The impulse response functions (figure 6) reinforce the results obtained in the benchmark specification. In line with the IRF of model 1, public debt shocks still do cause higher output. On the contrary, private debt shocks have a positive and milder impact in the short-run, but negative effects in the medium-run. In order to further investigate such results, in the next section, we consider disaggregated private debt series. 

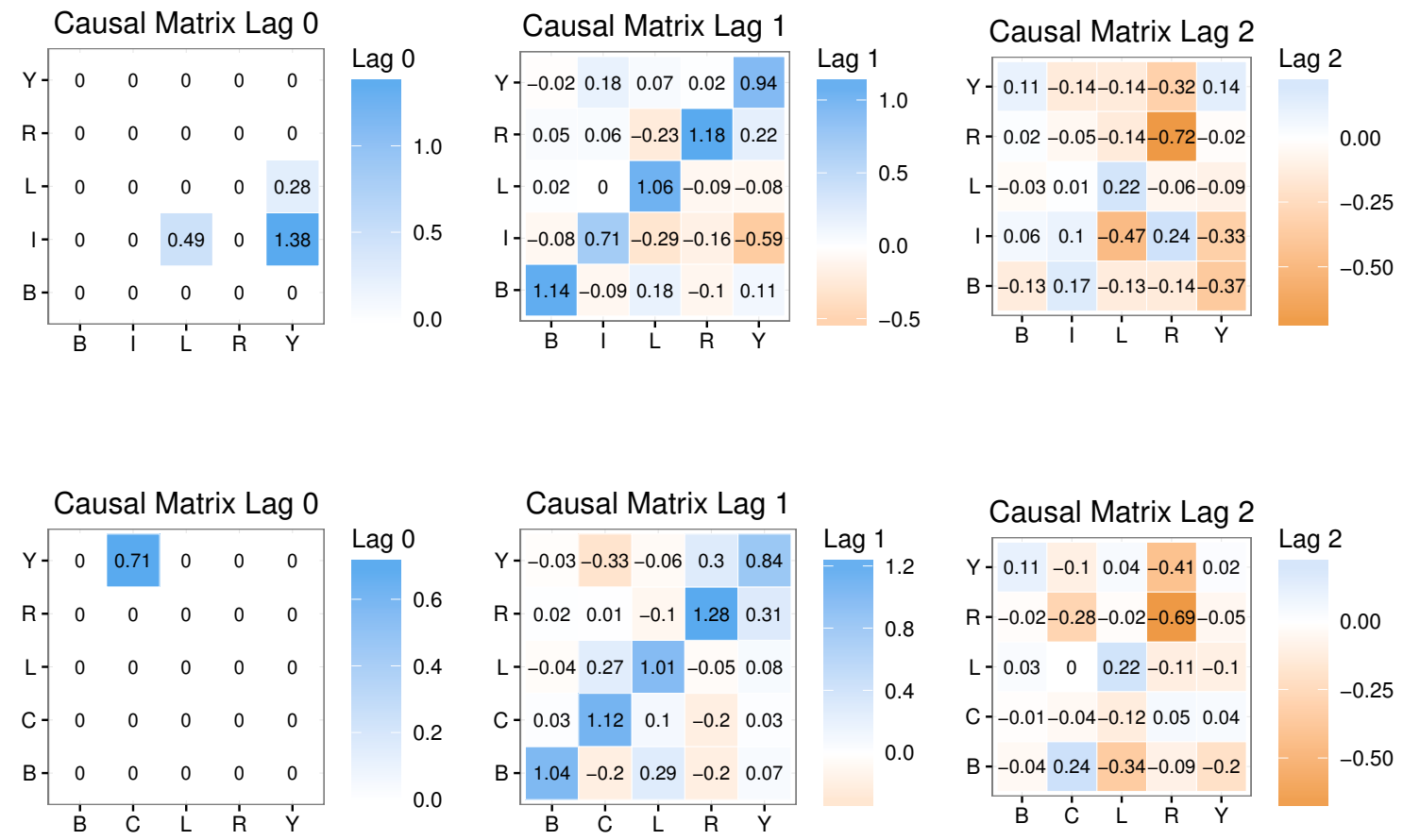

Figure 5: SVAR causal matrices up to the second lag for the augmented models 2 (top panels) and 3 (bottom panels). The variables below the matrices cause the ones on the left.
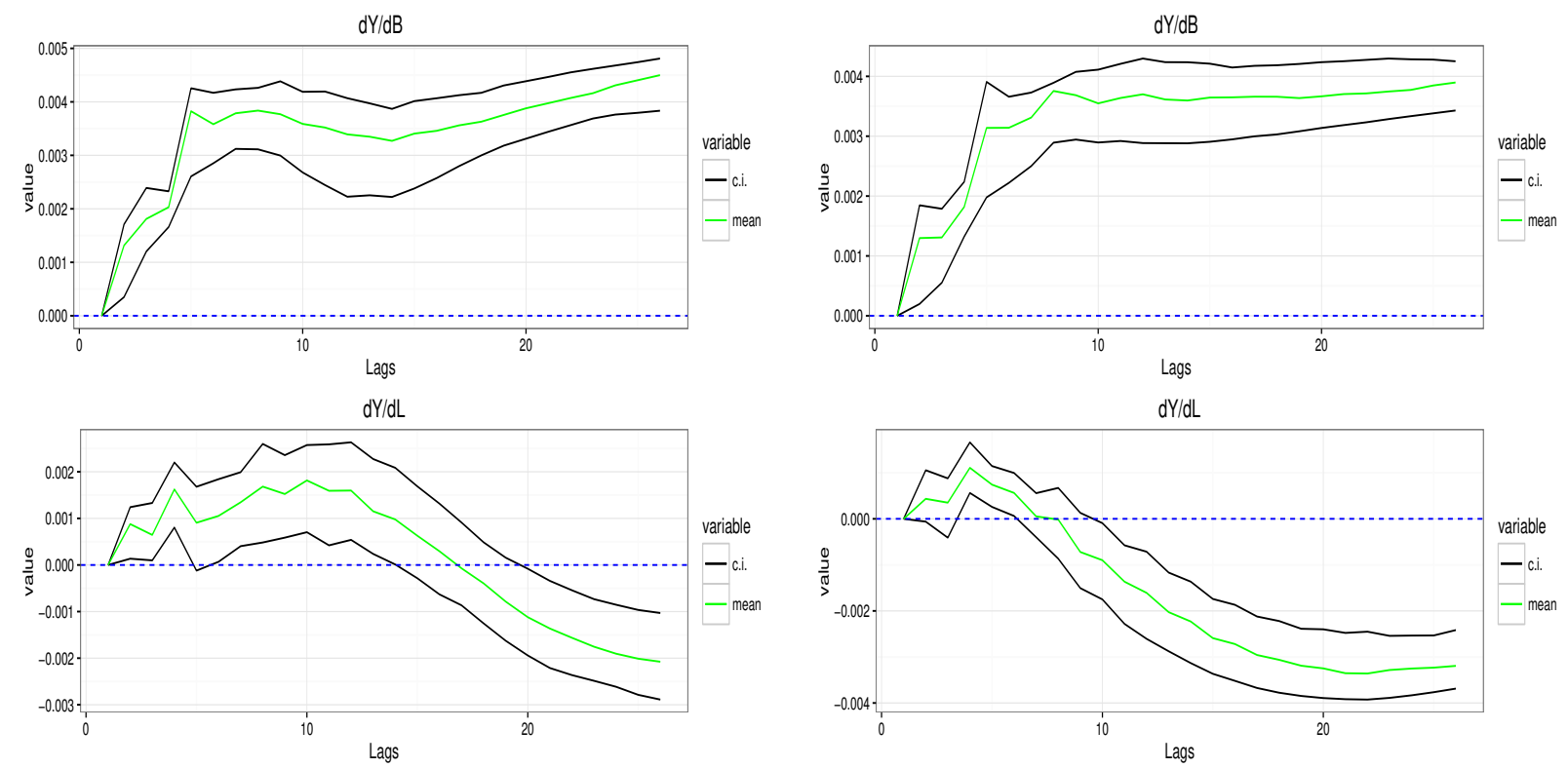

Figure 6: Impulse response functions, models 2 (left) and 3 (right). Response of GDP to a 1\% standard deviation shock to public debt (upper panels) and to private debt (lower panels). 95\% confidence bands obtained via bootstrap. 


\subsection{Disaggregated models}

We decompose the total private debt into its two main components: mortgage and corporate debts. This allows us to address the possible issue of having selected a bad proxy for aggregate private debt (even if it has been extensively used in the literature, see e.g. Jorda et al. 2014). Moreover, such a decomposition allows us to better understand how debt to different microeconomic actors (i.e. households and firms) can impact differently on output dynamics.

The new CVAR specifications adds to GDP, public debt and the 3-month T-Bill interest rate either corporate business debt and investment or mortgage debt and private consumption (cf. models 4 and 5 in table 3 ). The causal SVAR matrices for the scenario with disaggregated private debt series are presented in figure 7 The causal structure of the two models is very similar to the one of models 2 and 3 (cf. figure 5), suggesting that the dynamics of disaggregated private debt series is akin to the one of private debt. Moreover, lagged effects are consistent with all the previous regressions, thus further confirming that the "simple" baseline model is able to capture the lag structure.
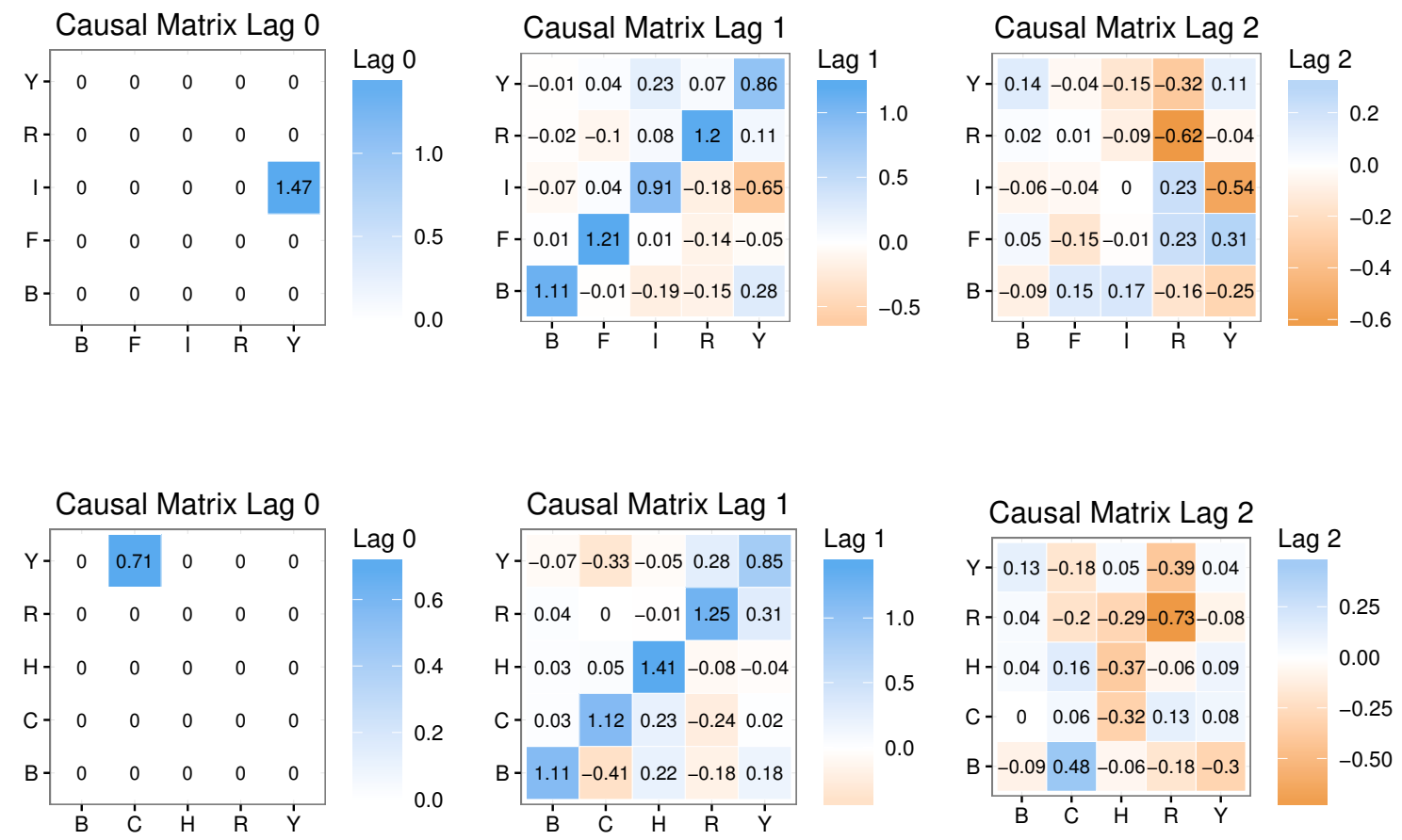

Figure 7: SVAR causal matrices up to the second lag for the disaggregated models 4 (top panels) and 5 (bottom panels). The variables below the matrices cause the ones on the left.

The impact of public, corporate and mortgages debt shocks are reported in the IRFs in figure 4.3 In line with our previous results, the effects of public debt shocks remain positive both in the short- and in the medium-run. The IRFs of mortgage and corporate debt provide a better understanding of the origin of the long-term negative effects of private debt. Indeed, we find that while corporate debt (left panel) has positive effects on GDP dynamics similar to those of public debt, mortgage debt shows strong negative effects in 
the medium-run (cf. figure 4.3) 11 Mortgage debt appears to be the main driver of aggregate private debt dynamics. The negative effects of mortgage credit may be due to its inflating impact on real asset prices, which possibly contribute to the emergence of bubbles (see Jorda et al. 2016). The positive effect of corporate debt on investment shows the positive link between credit and firms' real decisions.
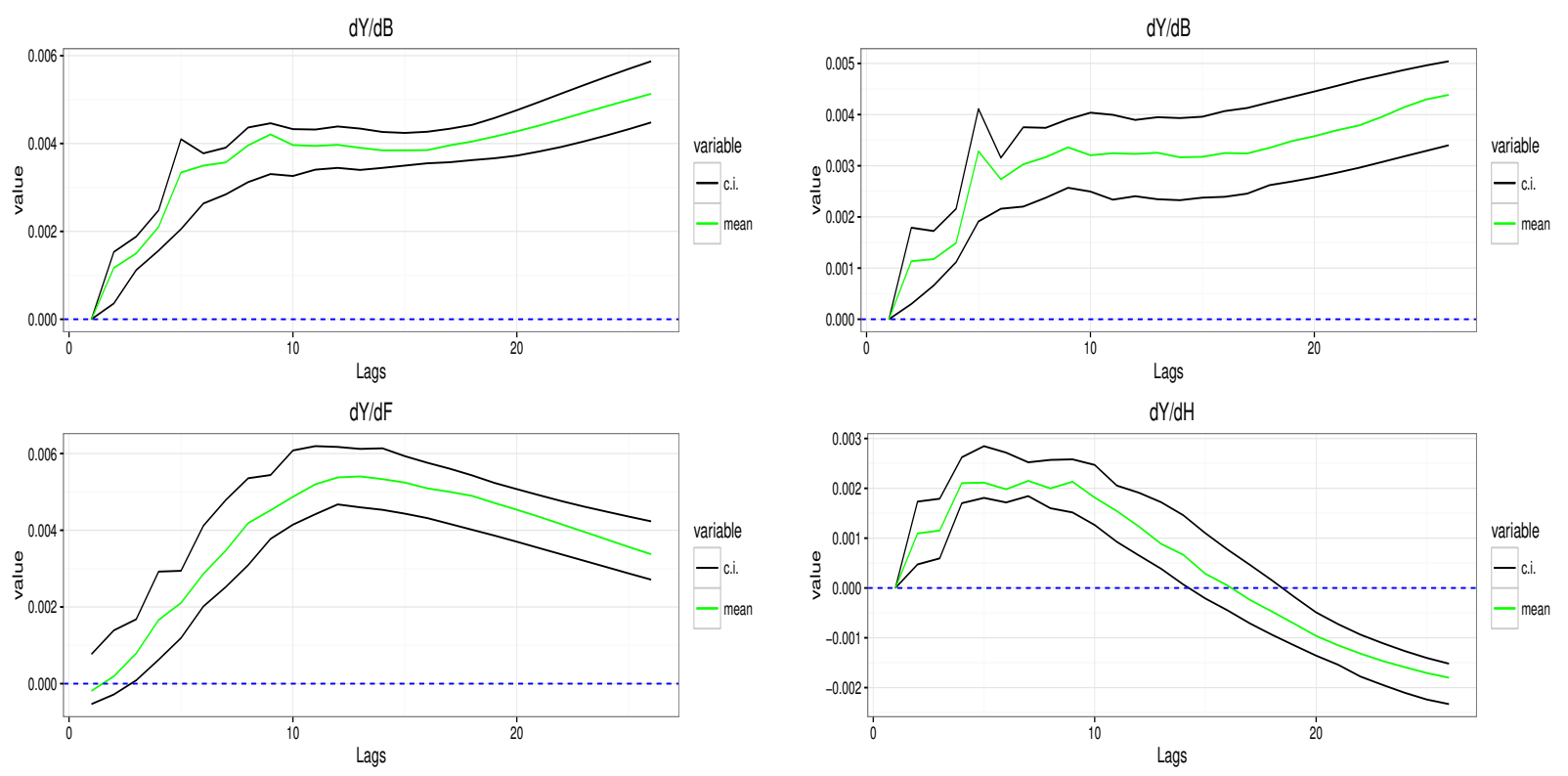

Figure 8: Impulse response functions, models 4 (left) and 5 (right). Response of GDP to a 1\% standard deviation shock to public debt (upper panels), to corporate debt (lower left panel) and to mortgage debt (lower right panel). $95 \%$ confidence bands obtained via bootstrap.

We now consider the reaction of private consumption and investment as to public and private debt shocks. In that, we also study the crowding-out or crowding-in effects of public expenditure and public debt. The textbook crowding-out hypothesis suggest a competing role between government and private expenditures: higher public consumption simply replaces private one or investment, even if government runs deficit and increases its debt (see Barro 1974 1989). On the contrary, the crowding-in hypothesis implies that government deficit not only does not "steal" any opportunity for the private sector, but it also spurs consumption and investment via higher aggregate demand (Woodford, 1990; Holmstrom and Tirole, 1998, Stiglitz, 2012).

The IRFs in figure 4.3 show the effects of public and private disaggregated debt shocks on aggregate private consumption and investment. Similarly to what happens to GDP, the IRFs suggest that public debt shocks have positive and persistent effects on both consumption and investment. Corporate debt also bear positive effects, on investment. Such results provide fresh new evidence supporting the crowding-in hypothesis. Instead, household debt boosts consumption only in the very short run, while the effects turn negative in the medium run, supporting once again the evidence showed above. Such a result might also be partially due to the increased ratio between adjustable-rate mortgages and fixed-rate ones that has occurred in the U.S. between 2000 and 2007 (see Furlong and Takhtamanova 2012) 12

\footnotetext{
${ }^{11}$ The negative long-run response of GDP to household debt shocks might be considered in contrast with the positive cointegrating relationship between the two variables. However, the equivalence between cointegrating relationship and causality among a set of variable is problematic, as it does not suggest a causal direction. This is why one should refer to the results produced by structural models.

${ }^{12}$ Adjustable-rate mortgages are indeed characterized by a low and fixed interest rate for the first two or three years (and indeed
} 

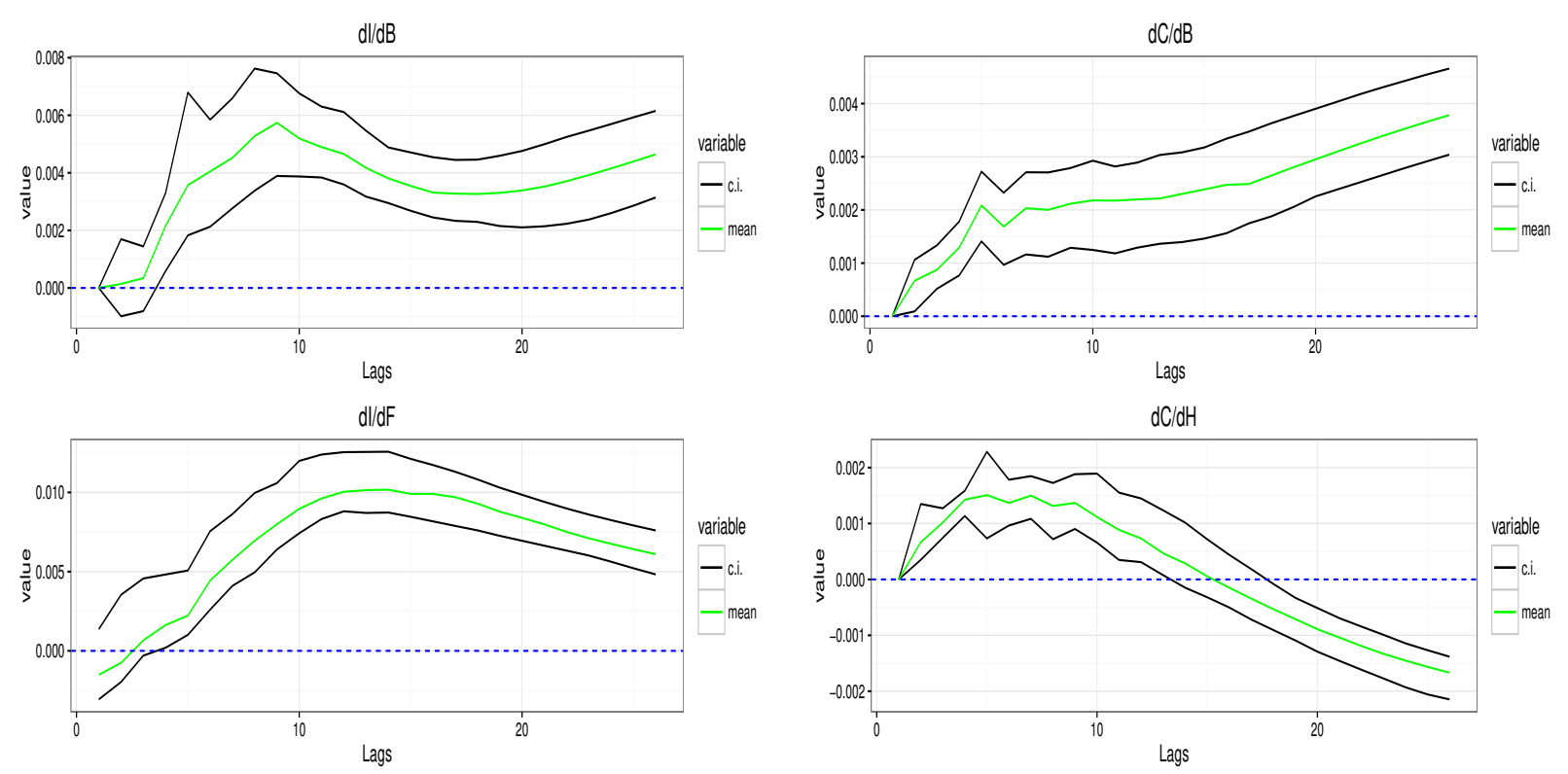

Figure 9: Impulse response functions, models 4 (left) and 5 (right). Response of investment (left) and consumption (right) to a $1 \%$ standard deviation shock to public debt (upper panels), to corporate debt (lower left panel) and to mortgage debt (lower right panel). 95\% confidence bands obtained via bootstrap.

\section{Robustness analysis}

In this section, we test the robustness of the results vis-à-vis the time period considered for the econometric analysis and for alternative specifications of the structural CVAR model.

Let us begin by assessing how the inclusion of the Great Recession in our sample period has affected the econometric results of the models. More specially, we jettison the post-2008 observations, and we estimate the model for the period from 1966 (Q1) to 2008 (Q3). The causal matrices in figure 10 show that the relations entailed in the full-sample models robustly hold and there are only mild changes in the magnitudes of the effects. Moreover, the impulse-response functions (cf. figure 11) confirm the results obtained employing the whole sample: public debts shocks still spur output growth. The unique difference is that the IRF of private debt shifts up, suggesting that the Great Recession has reduced the (positive) impact of private debt on GDP dynamics.

We then check the robustness of the results with respect to alternative model specifications. First, we consider alternative deflators. In all the setting presented in section 4 real consumption and investment has been obtained employing the GDP-deflator. When we adopt the consumption and investment deflators (models $2_{d f}$ and $3_{d f}$ in table 3 , the IRF results do not substantially change (see figure 12 , ${ }^{13}$ Moreover, in model 6, (see table 3 ) we replace the 3-months T-Bill interest rate with the 10-years one (cf. table 1), as households and firms might take their decision according to long-term interest rates. Results in figure 13 (left panel) are consistent with the previously presented evidence. Finally, in model 7, we augment the baseline specification adding government expenditure, to control for the main source of public debt and to possibly account for the up to the $12^{\text {th }}$ lag the household debt has a positive effect on consumption). Then, the interest rate is adjusted by the bank (typically upward), possibly causing a negative effect on consumption.

${ }^{13}$ Also the results related to the causal structures, which are available from the authors upon request, are fully compatible with the ones presented in models 2 and 3. 

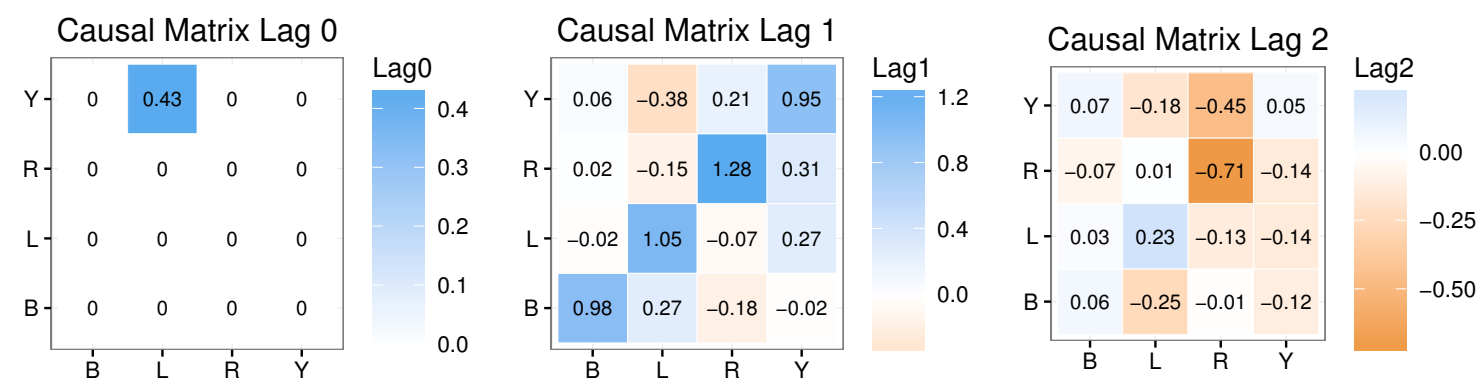

Figure 10: SVAR causal matrices up to the second lag for the baseline model 1 estimated in the period 19662008. The variables below the matrices cause the ones on the left.
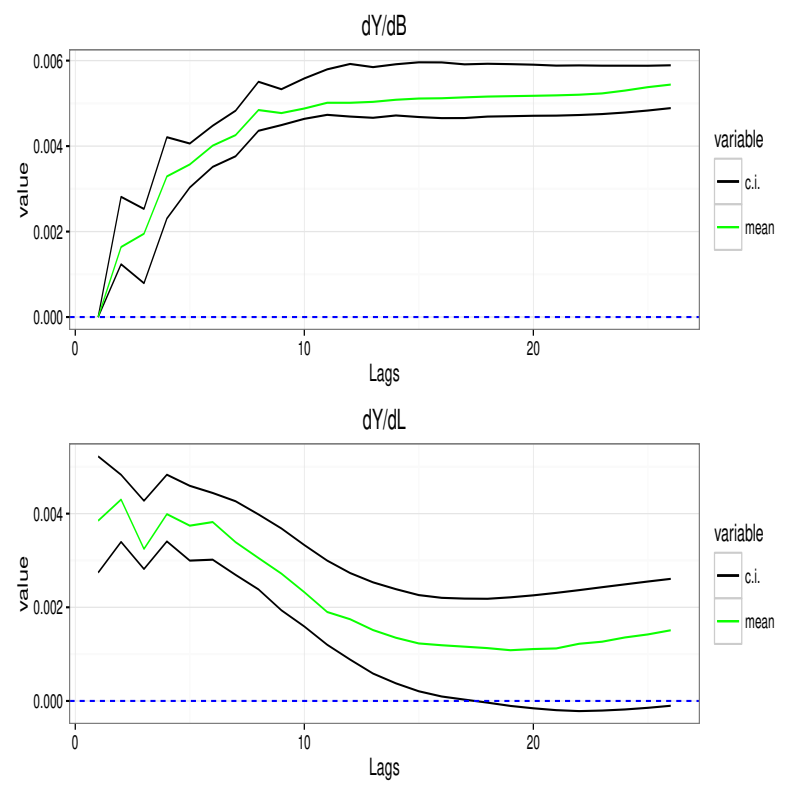

Figure 11: Impulse response functions, models $1_{n c}$. Response of GDP to a $1 \%$ standard deviation shock to public debt (upper panel) and to private debt (lower panel). 95\% confidence bands obtained via bootstrap. 

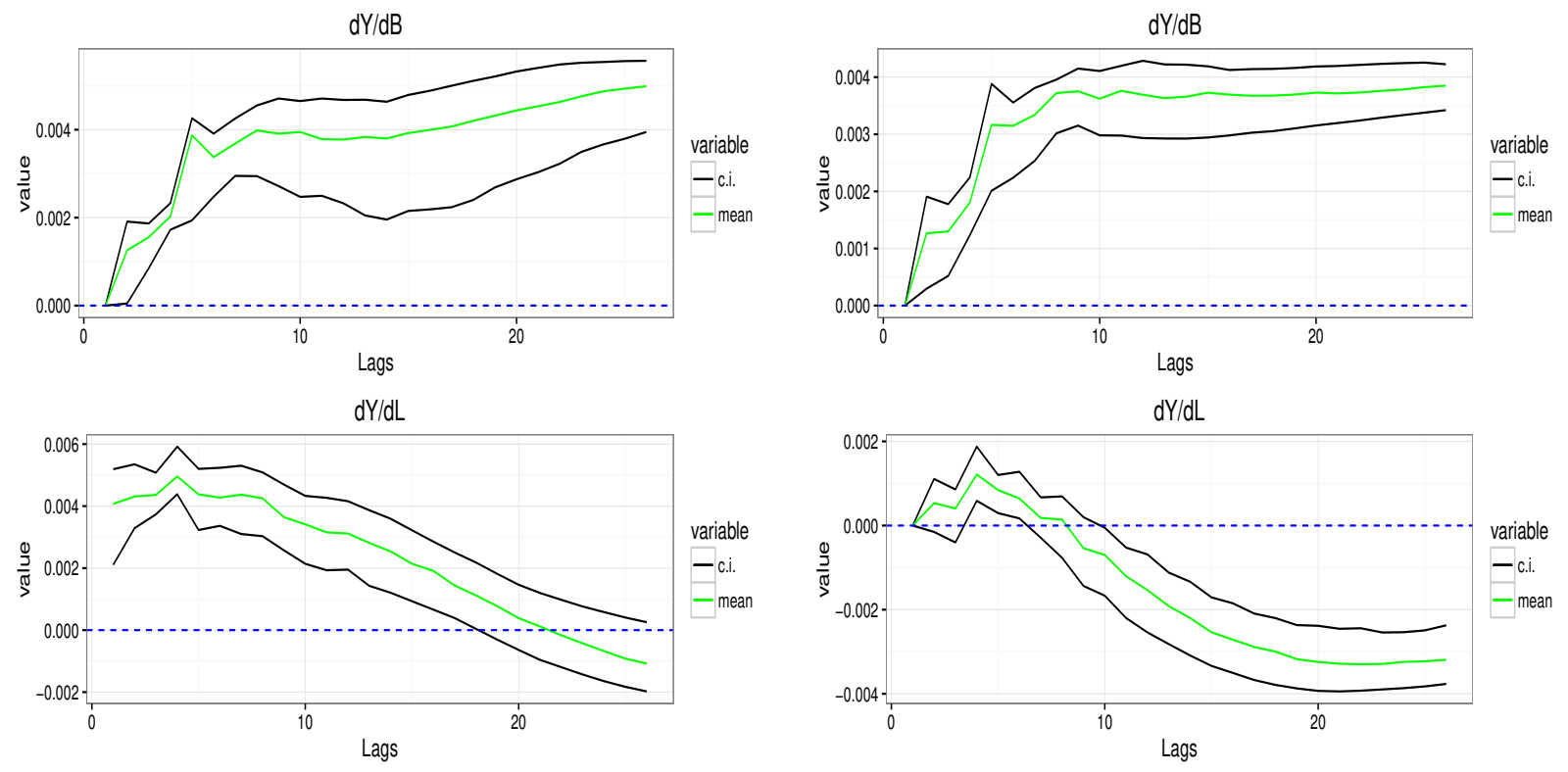

Figure 12: Impulse response functions, models $2_{d f}$ (left) and $3_{d f}$ (right). Response of GDP to a $1 \%$ standard deviation shock to public debt (upper panels) and to private debt (lower panels). 95\% confidence bands obtained via bootstrap.
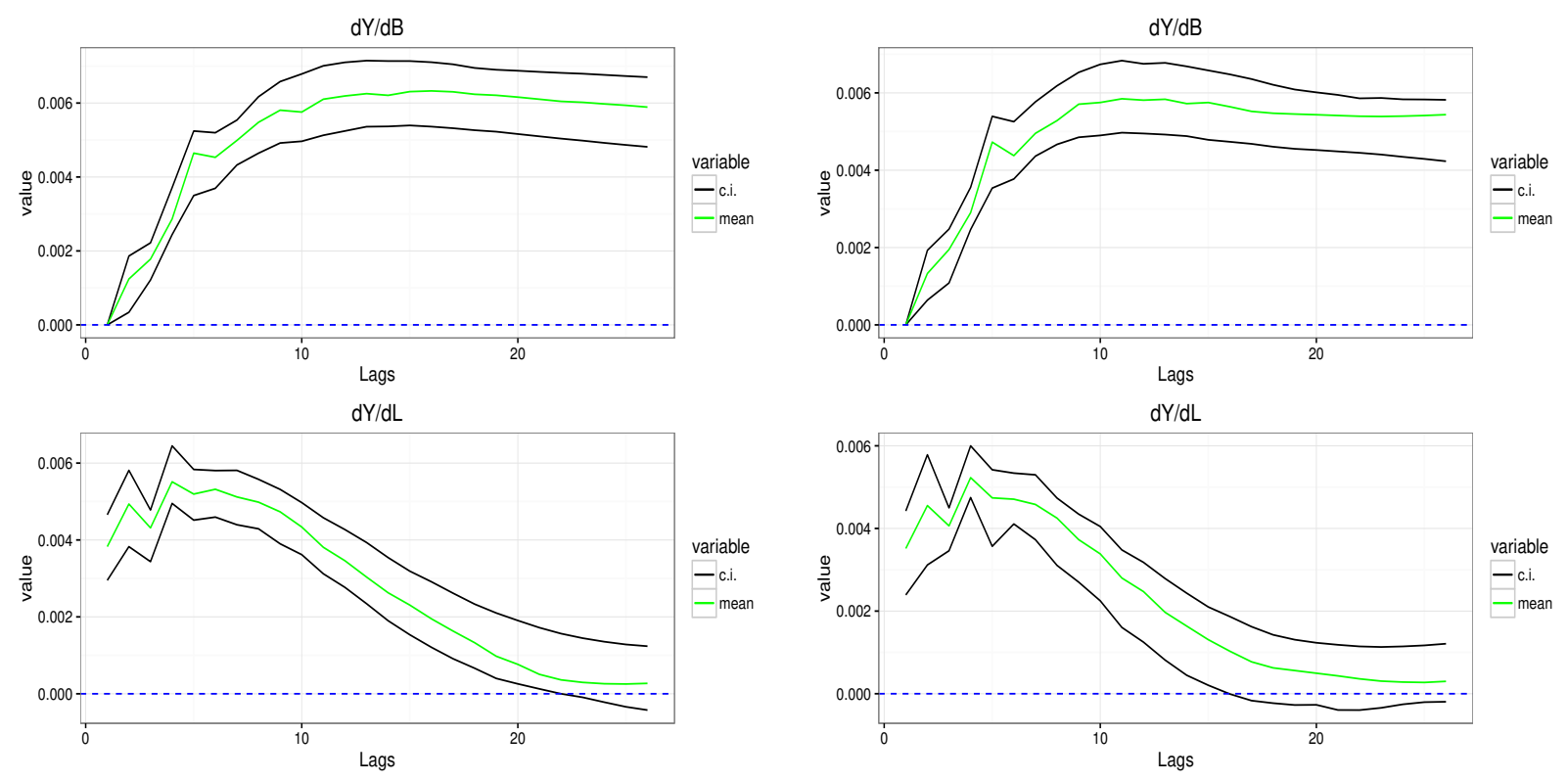

Figure 13: Impulse response functions, models 6 (left) and 7 (right). Response of GDP to a 1\% standard deviation shock to public debt (upper panels) and to private debt (lower panels). 95\% confidence bands obtained via bootstrap. 


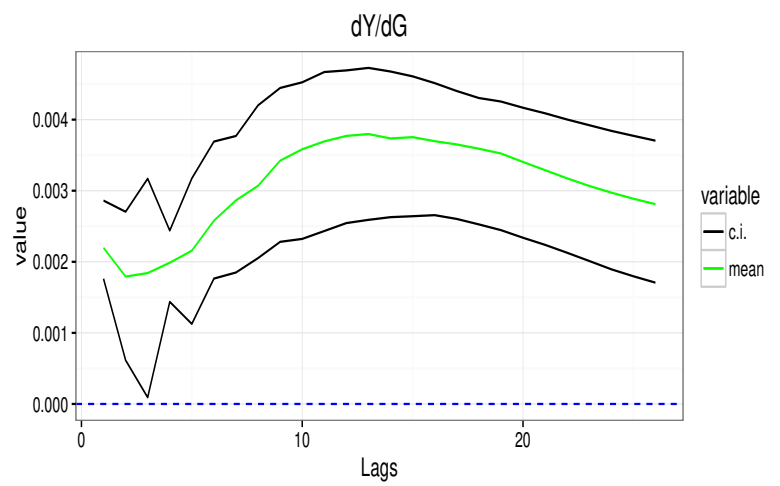

Figure 14: Impulse response functions, models 7. Response of GDP to a 1\% standard deviation shock to public expenditure. 95\% confidence bands obtained via bootstrap.

magnitude of the fiscal multiplier. The results showed by the IRFs in figure 13 (right panel) are consistent with the previously presented evidence. In particular, public expenditure shocks has a positive impact on GDP (see figure 14, suggesting a Keynesian transmission mechanisms for the positive effects of public debt ${ }^{14}$

\section{Conclusions}

In this paper, we have studied the effects of public and private debt shocks on GDP dynamic employing a battery of cointegrated VAR models, which have been identified employing the novel data-driven Independent Component Analysis (ICA) in order to obtain structural models purged of ad-hoc theoretical restrictions.

The analysis of the ensuing impulse response functions shows that public debt shocks positively and persistently affect GDP dynamics. In particular, we find that public debt shocks crowd-in private consumption and investment expenditure. We thus provide a fresh new piece of evidence to the debate on the role of public debt on growth (see Reinhart and Rogoff 2010b; Cecchetti et al. 2011; Minea and Parent, 2012; Herndon et al. 2013 Egert. 2015). Moreover, such a result appears to be robust to different model specifications and to the inclusion/exclusion of the Great Recession in the time sample.

At the same time, the effects of private debt are positive but milder, and they die out in the medium-run. In addition, in line with recent growing literature (see Mian and Sufi, 2009, Jorda et al. 2013, Batini et al., 2016), we find a strong negative association between household mortgage debt and private consumption and GDP in the medium-run. This result corroborates the hints from the financial frictions literature (see e.g. Brunnermeier et al. 2012) suggesting that financial and real crises are generated by real asset bubbles interplaying with fast mortgage debt expansions.

The coexistence of positive effects of public debt with negative ones stemming from household debt points to the fanus-faced impact of debt on economic activity.

Our work could be extended in at least two ways. First, we could account for possible existing nonlinearities between public debt and GDP dynamics employing Threshold Vector Auto-Regression models (as in Ferraresi et al. 2015, Proaño et al. 2014). Moreover, our analysis could be extended to other developed

\footnotetext{
${ }^{14}$ We also estimate models where we consider the ratio of public and private debt over GDP and richer specification encompassing GDP, public debt, firm debt, mortgage debt, consumption, investment and the 3-month T-Bill interest rate. Our results hold also in such models (the related IRFs are available from the authors upon request.)
} 
economies to search for possible heterogeneous effecst of public and private debt and the dynamics of the economy.

\section{Acknowledgments}

We are indebted to Kevin D. Hoover, Herbert Dawid, Davide Fiaschi and Fulvio Corsi for useful comments and suggestions on preliminary versions of the paper. Thanks also to the participants at the conferences WEHIA 2016 (Castellon de la Plana) and CRISIS 2016 (Ancona). MG, MN and AR acknowledge financial support from the European Union Horizon 2020 research and innovation programme under grant agreement No. 649186 (ISIGrowth). AM acknowledges financial support from the Institute for New Economic Thinking under grant agreement INO15-00021. 


\section{References}

Ahelegbey, D. F., M. Billio and R. Casarin (2016), "Bayesian Graphical Models for Structural Vector Autoregressive Processes”, fournal of Applied Econometrics, 31: 357-386.

Barro, R. J. (1974), “Are Government Bonds Net Wealth?”, fournal of Political Economy, 82: 1095-1117.

Barro, R. J. (1989), “The Ricardian Approach to Budget Deficits”, The fournal of Economic Perspectives, 3: 37-54.

Batini, N., G. Melina and S. Villa (2016), "Fiscal Buffers, Private Debt, and Stagnation: The Good, the Bad and the Ugly", Technical Report 16-104, IMF Working Paper.

Bernanke, B., M. Gertler and S. Gilchrist (1999), "The Financial Accelerator in a Quantitative Business Cycle Framework”, in J. Taylor and M. Woodford, (eds.), Handbook of Macroeconomics, Elsevier Science: Amsterdam.

Bessler, A. D. and S. Lee (2002), "Money and prices: U.S. Data 1869-1914 (A study with directed graphs)", Empirical Economics, 27: 427-446.

Brunnermeier, M. K., T. M. Eisenbach and Y. Sannikov (2012), "Macroeconomics with Financial Frictions: A Survey", Working paper 18102, National Bureau of Economic Research.

Cecchetti, S., M. Mohanty and F. Zampolli (2011), “The real effects of debt”, BIS Working Papers 352, Bank for International Settlements.

Checherita-Westphal, C. and P. Rother (2010), "The Impact of High and Growing Government Debt on Economic Growth: An Empirical Investigation for the Euro Area”, Working Paper Series 1237, European Central Bank.

Delli Gatti, D., M. Gallegati, B. Greenwald, A. Russo and J. Stiglitz (2010), “The Financial Accelerator in an Evolving Credit Network”, Journal of Economic Dynamics and Control, 34: 1627-1650.

Demiralp, S. and K. D. Hoover (2003), "Searching for the Causal Structure of a Vector Autoregression*", Oxford Bulletin of Economics and Statistics, 65: 745-767.

Dosi, G., G. Fagiolo, M. Napoletano and A. Roventini (August 2013), "Income distribution, credit and fiscal policies in an agent-based Keynesian model”, Journal of Economic Dynamics and Control, 37: 1598-1625.

Dosi, G., G. Fagiolo, M. Napoletano, A. Roventini and T. Treibich (March 2015), "Fiscal and Monetary Policies in Complex Evolving Economies”, Journal of Economic Dynamics and Control, 52: 166-189.

Eberhardt, M. and A. F. Presbitero (2015), "Public Debt and Growth: Heterogeneity and Non-linearity", fournal of International Economics, 97: 45-58.

Egert, B. (2015), “Public debt, economic growth and nonlinear effects: Myth or reality?", fournal of Macroeconomics, 43: 226-238.

Eggertsson, G. B. and P. Krugman (2012), "Debt, deleveraging, and the liquidity trap: A Fisher-Minsky-Koo approach", The Quarterly fournal of Economics, 127: 1469-1513.

Ferraresi, T., A. Roventini and G. Fagiolo (2015), "Fiscal Policies and Credit Regimes: A TVAR Approach”, fournal of Applied Econometrics, 30: 1047-1072.

Fisher, I. (1933), “The Debt-Deflation Theory of Great Depressions”, Econometrica, 1: 337-357. 
Furlong, F. and Y. Takhtamanova (2012), “Did the Housing Boom Affect Mortgage Choices?”, Federal Reserve Bank of San Francisco Economic Letter, .

Gertler, M., N. Kiyotaki et al. (2010), "Financial intermediation and credit policy in business cycle analysis", Handbook of monetary economics, 3: 547-599.

Gourieroux, C., A. Monfort and J. P. Renne (2017), "Statistical inference for independent component analysis: Application to structural VAR models", Journal of Econometrics, 196: 111-126.

Greenwald, B. C. and J. E. Stiglitz (1993), "Financial market imperfections and business cycles”, The Quarterly fournal of Economics, 108: 77-114.

Herndon, T., M. Ash and R. Pollin (2013), "Does high public debt consistently stifle economic growth? A critique of Reinhart and Rogoff”, Cambridge fournal of Economics, 38: 257-279.

Holmstrom, B. and J. Tirole (1998), "Private and public supply of liquidity", fournal of Political Economy, 106: 1-40.

Hyvarinen, A., J. Karhunen and E. Oja (2001), Indepentent Component Analysis, Wiley.

Hyvarinen, A., K. Zhang, S. Shimizu and P. O. Hoyer (2010), "Estimation of a Structural Vector Autoregression Model Using Non-Gaussianity”, Journal of Machine Learning Research, 11: 1709-1731.

Johansen, S. (1995), Likelihood-based Inference in Cointegrated Vector Autoregressive Models, Oxford University Press.

Johansen, S. and K. Juselius (1990), "Maximum Likelihood Estimation and Inference on Cointegration - With Applications to the Demand for Money", Oxford Bulletin of Economics and Statistics, 52: 169-210.

Johansen, S. and K. Juselius (1994), "Identification of the long-run and the short-run structure an application to the ISLM model”, fournal of Econometrics, 63: 7-36.

Jorda, O., M. Schularick and A. M. Taylor (2013), "When Credit Bites Back”, fournal of Money, Credit and Banking, 45: $3-28$.

Jorda, O., M. Schularick and A. M. Taylor (2014), "Private Credit and Public Debt in Financial Crises”, Economic Letter 2014-07, FRBSF.

Jorda, O., M. Schularick and A. M. Taylor (2016), “The great mortgaging: housing finance, crises and business cycles”, Economic Policy, 31: 107-152.

Koo, R. (2008), The Holy Grail of Macroeconomics: Lessons from fapan’s Great Recession, Wiley: NewYork.

Lutkepohl, H. (1991), Introduction to multiple time series analysis, Springer-Verlag.

Mian, A. and A. Suf (2009), "The Consequences of Mortgage Credit Expansion: Evidence from the U.S. Mortgage Default Crisis”, The Quarterly fournal of Economics, 124: 1449-1496.

Mian, A. and A. Sufi (2011), "House Prices, Home Equity-Based Borrowing, and the US Household Leverage Crisis", American Economic Review, 101: 2132-2156.

Mian, A., A. Sufi and V. Emil (2015), "Household Debt and Business Cycles Worldwide”, Working Paper 21581, NBER.

Minea, A. and A. Parent (2012), "Is High Public Debt Always Harmful to Economic Growth? Reinhart and Rogoff and some complex nonlinearities”, Working Papers 12-08, Association Francaise de Cliometrie (AFC). 
Minsky, H. P. (1986), Stabilizing an Unstable Economy, 144 .

Moneta, A. (2008), "Graphical causal models and VARs: an empirical assessment of the real business cycles hypothesis", Empirical Economics, 35: 275-300.

Moneta, A., D. Entner, P. O. Hoyer and A. Coad (2013), "Causal Inference by Independent Component Analysis: Theory and Applications", Oxford Bulletin of Economics and Statistics, 75: 705-730.

$\mathrm{Ng}$, S. and J. H. Wright (December 2013), "Facts and Challenges from the Great Recession for Forecasting and Macroeconomic Modeling”, fournal of Economic Literature, 51: 1120-54.

Panizza, U. and A. Presbitero (2013), "Public Debt and Economic Growth in Advanced Economies: A Survey", Swiss fournal of Economics and Statistics, 149: 175-204.

Panizza, U. and A. F. Presbitero (2014), “Public Debt and Economic Growth: Is There a Causal Effect?”, fournal of Macroeconomics, 41: 21-41.

Phillips, P. C. B. and P. Perron (1988), “Testing for a unit root in time series regression”, Biometrika, $75: 335$.

Proaño, C. R., C. Schoder and W. Semmler (2014), "Financial stress, sovereign debt and economic activity in industrialized countries: Evidence from dynamic threshold regressions”, fournal of International Money and Finance, 45: 17 - 37.

Reinhart, C. M., V. R. Reinhart and K. S. Rogoff (2012), "Public Debt Overhangs: Advanced-Economy Episodes since 1800", fournal of Economic Perspectives, 26: 69-86.

Reinhart, C. M. and K. S. Rogoff (2010a), “Growth in a Time of Debt”, American Economic Review, 100: 573-78.

Reinhart, C. M. and K. S. Rogoff (2010b), This Time Is Different: Eight Centuries of Financial Folly, Princeton University Press.

Schularick, M. and A. M. Taylor (2012), "Credit Booms Gone Bust: Monetary Policy, Leverage Cycles, and Financial Crises, 1870-2008”, American Economic Review, 102: 1029-1061.

Shimizu, S., P. O. Hoyer, A. Hyvarinen and A. J. Kerminen (2006), "A Linear Non-Gaussian Acyclic Model for Causal Discovery”, fournal of Machine Learning Research, 7: 2003-2030.

Silvapulle, P. S. and J. M. Podivinsky (2000), "The effect of non-normal disturbances and conditional heteroskedasticity on multiple cointegration tests”, Journal of Statistical Computation and Simulation, 65: 173-189.

Stiglitz, J. E. (2012), “Stimulating the Economy in an Era of Debt and Deficit”, The Economists’ Voice, 9.

Stock, J. and M. Watson (1999), Business Cycle Fluctuations in U.S. Macroeconomic Time Series, Amsterdam: Elsevier, 3-64.

Swanson, N. R. and C. W. J. Granger (1997), "Impulse Response Functions Based on a Causal Approach to Residual Orthogonalization in Vector Autoregressions”, fournal of the American Statistical Association, 92: 357-367.

Turner, A. (2015), Between Debt and the Devil: Money, Credit, and Fixing Global Finance, Princeton University Press.

Woodford, M. (1990), "Public debt as private liquidity”, American Economic Review, 80: 382?388. 


\section{Appendix A The VARLiNGAM Algorithm}

(1) Estimate the reduced form VAR model of equation (2) obtaining estimates $\hat{\mathbf{A}}_{\mathbf{i}}$ of the matrices $\mathbf{A}_{\mathbf{i}}, \forall \mathbf{i}=\mathbf{1}, \ldots, \mathbf{p}$. Denote by $\hat{\mathbf{U}}$ the $K \times T$ matrix of the corresponding estimated VAR error terms, that is each column of $\hat{\mathbf{U}}$ is $\hat{\mathbf{u}}_{\mathbf{t}} \equiv\left(\hat{u}_{1 t}, \ldots, \hat{u}_{K t}\right)^{\prime}, \forall t=1, \ldots, T$. Check whether the $u_{i t}$ (for all rows i) indeed are non-Gaussian, and proceed only if this is so.

(2) Use FastICA or any other suitable ICA algorithm (Hyvarinen et al. 2001) to obtain a decomposition $\hat{\mathbf{U}}=\mathbf{P E}$ where $\mathbf{P}$ is $K \times K$ and $\mathbf{E}$ is $K \times T$, such that the rows of $\mathbf{E}$ are the estimated independent components of $\hat{\mathbf{U}}$. Then validate non-Gaussianity and (at least approximate) statistical independence of the components before proceeding.

(3) Let $\tilde{\tilde{\Gamma}}_{\mathbf{0}}=\mathbf{P}^{-1}$. Find $\tilde{\boldsymbol{\Gamma}}_{\mathbf{0}}$, the row-permutated version of $\tilde{\tilde{\Gamma}}_{\mathbf{0}}$ which minimizes $\sum_{i} \frac{1}{\left|\tilde{\boldsymbol{\Gamma}}_{\mathbf{0}, \mathrm{ii}}\right|}$ with respect to the permutation. Note that this is a linear matching problem which can be easily solved even for high $\mathrm{K}$ (Shimizu et al. 2006).

(4) Divide each row of $\tilde{\Gamma}_{0}$ by its diagonal element, to obtain a matrix $\hat{\Gamma}_{0}$ with all ones on the diagonal.

(5) Let $\tilde{\mathbf{B}}=\mathbf{I}-\hat{\boldsymbol{\Gamma}}_{\mathbf{0}}$.

(6) Find the permutation matrix $\mathbf{Z}$ which makes $\mathbf{Z} \tilde{\mathbf{B}} \mathbf{Z}^{\mathbf{T}}$ as close as possible to lower triangular. This can be formalized as minimizing the sum of squares of the permuted upper-triangular elements, and minimized using a heuristic procedure (Shimizu et al. 2006). Set the upper-triangular elements to zero, and permute back to obtain $\hat{\mathbf{B}}$ which now contains the acyclic contemporaneous structure. (Note that it is useful to check that $\mathbf{Z} \tilde{\mathbf{B}} \mathbf{Z}^{\mathbf{T}}$ indeed is close to strictly lower-triangular).

(7) $\hat{\mathbf{B}}$ now contains $K(K-1) / 2$ non-zero elements, some of which may be very small (and statistically insignificant). For improved interpretation and visualization, it may be desired to prune out (set to zero) small elements at this stage, for instance using a bootstrap approach Shimizu et al. 2006).

(8) Finally, calculate estimates of $\boldsymbol{\Gamma}_{\mathbf{i}}, \forall \mathbf{i}=\mathbf{1}, \ldots, \mathbf{p}$ for lagged effects using $\boldsymbol{\Gamma}_{\mathbf{i}}=(\mathbf{I}-\hat{\mathbf{B}}) \hat{\mathbf{A}}_{\mathbf{i}}$.

\section{Appendix B Testing the Assumptions of the ICA Algorithm}

At the base of our causal search algorithm stand two important assumptions:

- A1: the residuals are linear combinations of underlying components that are mutually independent;

- A2: the residuals are linear combinations of underlying components that are non-Gaussian (with at most one of them Gaussian).

But the second assumption might also be relaxed and replaced by its milder version:

- A2 bis: the residuals are linear combinations of underlying components that are jointly non-Gaussian.

The typical assumption required for SVAR is orthogonality - i.e. absence of dependencies in the first moment which is testable. Our causal search strategy instead requires independence - i.e. absence of dependencies in all the moments - that instead cannot be tested. Testing for absence of correlation at least, allows us to obtain a first indication for the fact that, the assumption is not rejected (up to the first order). We test this via a bivariate graphical inspection and via simple OLS regressions. The results in figure 15 are presented only for the first model for sake of brevity, but for all the models presented in table 3 the results are very similar, indicating that the structural shocks do not present clear patterns and that we cannot reject the independence assumption ${ }^{15}$

\footnotetext{
${ }^{15}$ Results and graphs for the other models are available from the authors upon request.
} 

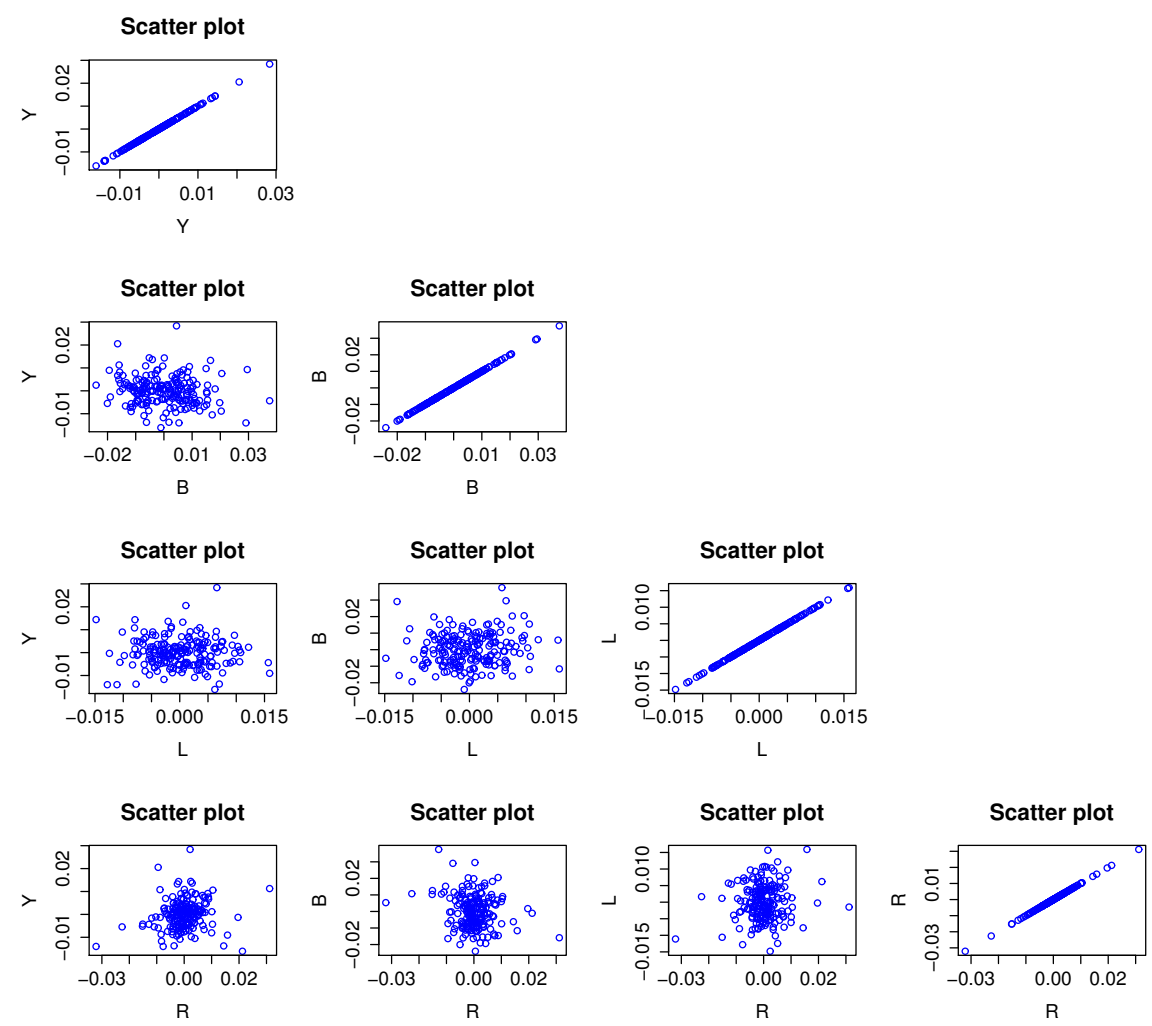

Figure 15: Independence test on the structural residuals of the baseline models 1.

Also a statistical analysis by means of OLS suggest that this is the case. In fact by running simple linear regressions of the type:

$$
\varepsilon_{i}=\beta \varepsilon_{j}
$$

where $i$ and $j$ stand for the residuals of two different variables, allows one again to check whether some linear relations between the structural residuals $\varepsilon_{i}$ and $\varepsilon_{j}$ exists. Table 5 presents the results for the first baseline model. For the others models the results are very similar and allow us to conclude that in this case the independence of the structural shocks is an assumption which is satisfied. Indeed only few times some parameters result slightly significant at the $5 \%$ while they never are at the $1 \%$, indicating that their independence might be a not too much restrictive assumption in this case.

The second assumption is instead more easily testable and we do that via Shapiro-Wilk test for normality on the residuals. The (reduced form) residuals are linear combinations of the underlying components (the structural shocks) and since a linear combination of Gaussian components would necessarily imply Gaussian residuals as well, if the residuals are non-Gaussian, they must have been generated by non-Gaussian components ${ }^{16}$ In table 6 we check that the assumption A2 or that at least its milder version, A2 bis is satisfied. From the first row, it is easy to see that at least the assumption A2 bis is always satisfied. After a more detailed check, we see that the strict version is satisfied in 3 out of 5 cases (the models with ID 1, 2 and 4). We therefore conclude that the conditions are met and the ICA algorithm is here applicable quite safely.

\footnotetext{
${ }^{16}$ Notice here that the rejection of $H_{0}$ stands for non-Gaussianity.
} 


\begin{tabular}{lcccc}
\hline Equation & Coefficient & Standard Error & t statistic & $p$-value \\
\hline $\mathrm{Y}=\mathrm{f}(\mathrm{B})$ & -0.08658981 & 0.04535515 & -1.9091505 & 0.05774169 \\
$\mathrm{Y}=\mathrm{f}(\mathrm{L})$ & -0.04699905 & 0.08438565 & -0.5569554 & 0.57820994 \\
$\mathrm{Y}=\mathrm{f}(\mathrm{R})$ & 0.15871436 & 0.06997094 & 2.2682896 & 0.02443041 \\
& -0.08485211 & 0.04570988 & -1.8563190 & 0.06495647 \\
$\mathrm{Y}=\mathrm{f}(\mathrm{B}, \mathrm{L})$ & -0.03061003 & 0.08431399 & -0.3630480 & 0.71697261 \\
& & & & \\
$\mathrm{Y}=\mathrm{f}(\mathrm{B}, \mathrm{R})$ & -0.07105341 & 0.04569677 & -1.5548891 & 0.12163660 \\
& 0.13977211 & 0.07076914 & 1.9750431 & 0.04971154 \\
$\mathrm{Y}=\mathrm{f}(\mathrm{L}, \mathrm{R})$ & -0.06442700 & 0.08376427 & -0.7691466 & 0.44276133 \\
& 0.16355376 & 0.07032789 & 2.3255889 & 0.02109609 \\
& -0.06774527 & 0.04612290 & -1.4687989 & 0.14354977 \\
$\mathrm{Y}=\mathrm{f}(\mathrm{B}, \mathrm{L}, \mathrm{R})$ & -0.04929656 & 0.08414325 & -0.5858647 & 0.55866539 \\
& 0.14435692 & 0.07132240 & 2.0240053 & 0.04437743 \\
\hline \hline
\end{tabular}

Table 5: OLS regressions allowing to check for independence of the structural shocks

\begin{tabular}{lccccc}
\hline Variable & $I D ~ 1$ & $I D ~ 2 ~$ & $I D ~ 3$ & $I D ~ 4$ & $I D ~ 5$ \\
\hline joint & 0.000 & 0.000 & 0.000 & 0.000 & 0.000 \\
$u_{Y}$ & 0.001 & 0.001 & 0.062 & 0.004 & 0.100 \\
$u_{B}$ & 0.028 & 0.024 & 0.014 & 0.540 & 0.001 \\
$u_{L}$ & 0.879 & 0.113 & 0.378 & & \\
$u_{F}$ & & & & 0.062 & \\
$u_{H}$ & & & & & 0.295 \\
$u_{I}$ & & 0.941 & & 0.072 & \\
$u_{C}$ & & & 0.030 & & 0.107 \\
$u_{R_{3 m}}$ & 0.000 & 0.000 & 0.000 & 0.000 & 0.000 \\
\hline \hline
\end{tabular}

Table 6: Shapiro-Wilk test for non-Gaussianity p-values. $H_{0}=$ Gaussianity 